\title{
Stock return anomalies: Evidence from the Johannesburg Stock Exchange
}

\begin{abstract}
This paper investigates the presence of stock return anomalies for stocks listed on the Johannesburg Stock Exchange, covering the period from 1985 to 2010 . Explanatory variables include market capitalization, book-to-market equity ratio, momentum in stock returns, net share issues, yield-to-book equity ratio, accrual of operational assets and growth in total assets. It is demonstrated that the sorted returns approach, compared to either correlation or regression analysis, provides much more detailed information regarding the relationships between explanatory variables and stock returns. We find that the anomalous behaviour of stocks on the JSE is in many respects similar to the behaviour observed by Fama and French on the NYSE, and that anomalous return behaviour is still present after compensating for risk. Different types of anomalous behaviour are present within different stock size categories. This study provides further evidence against accepting the EMH in its strong or semistrong form, as the information used is all publicly available.
\end{abstract}

\section{INTRODUCTION}

The basis of finance theory was formulated by Sharpe (1964) and Lintner (1965) in the form of the Capital Asset Pricing Model (CAPM), followed up by the work of Fama (1970) to formulate the efficient market hypothesis $(\mathrm{EMH})$. More recent studies by Banz (1981), Fama and French (1992) and others provided evidence that was contrary to the EMH, demonstrating empirical relationships between risk-adjusted stock returns and a variety of fundamental parameters, including market capitalisation (MC) and book-tomarket equity ratio $(B / M)$. In a study focussing on the mean-reversion phenomenon on the JSE Cubbins, Eidne, Firer and Gilbert (2006) demonstrate that for the period 1983 to 2005 stocks performing poorly over the previous 5 years on average outperform stocks that performed well over this period by $11,5 \%$ per annum during the subsequent 5 year period, providing further evidence against the EMH on the JSE.

These contradictions of CAPM and the EMH eventually became known as so-called stock return anomalies, against the background of evidence that the returns on specific categories of stocks could not be explained by market risk (e.g. the stock's beta) alone. This has led to numerous studies, on the one hand to investigate the size of anomalous returns, and on the other hand to find an explanation for such returns, in most cases trying to link the explanatory variables to some proxy for risk (Fama and French, 1992; Chan, Hamao and Lakonishok, 1991 and many others).

While these phenomena were widely studied on the larger financial markets (typically those of the USA, UK, Germany and Japan), comparatively less work was published about these aspects of the behaviour of

*School of Electrical, Electronic and Computer Engineering, Northwest University, Potchefstroom Campus, Private Bag X6001, Potchefstroom 2520, Republic of South Africa.

Email: alwyn.hoffman@nwu.ac.za financial markets in developing countries. This work reports on behaviour related to anomalous stock returns as observed on the Johannesburg Stock Exchange (JSE). A detailed overview is therefore provided in the literature review of historic evidence from this market relating to CAPM and the EHM and the existence of stock return behaviour that could be viewed as anomalous.

One difficulty that is encountered when trying to compare the often conflicting results from literature regarding market efficiency and anomalous returns is the lack of a uniform methodology used by different researchers to investigate the relationships that are potentially indicative of anomalous stock returns. Reviewing the above studies the approach that in the opinion of the author provides the most comprehensive quantified information on the presence of stock return anomalies is the methodology developed by Fama and French (2008 and earlier papers), which is based on a combination of sorted stock returns and crosssectional regression studies. None of the above references reporting on stock behaviour on the JSE used this comprehensive methodology or an alternative approach that provides the same level of detailed feedback on the quantified observations regarding stock return behaviour that may be viewed as anomalous. It was hence decided to more or less follow the approach as developed by Fama and French, with the addition of a correlation analysis study that was found to provide additional insights when comparing our results with those from other studies.

In order to provide as comprehensive answers as possible to the above questions, the study covers the period $1985-2010$, including as far as possible all stocks that were listed on the JSE at the respective time. The selected period is the maximum time period for which complete pricing and fundamental accounting information could be obtained for the majority of JSE listed stocks from the source of share data that was used (McGregorBFA). 
Against the above background this paper addresses the following questions:

- Can further evidence be generated against the acceptance of the Efficient Market Hypothesis, using a substantially larger data set than prior studies performed on the JSE, in the process disproving the null hypothesis that none of the explanatory variables investigated can be used to generate abnormal stock returns?

- Do stocks listed on the JSE display anomalous stock return behaviour similar to that observed by Fama and French (2008) for stocks listed on the NYSE when using data representing a sufficiently long time period to support such a comparison?

- Is the evidence produced by sorted returns, regression analysis and correlation analysis respectively in support of each other, or do these techniques generate conflicting evidence regarding stock return behaviour?

- Which of the three types of analysis provide the most complete and reliable evidence on anomalous stock returns? More specifically, does the sorted returns approach as developed by Fama and French (2008) provide substantial additional information regarding stock return behaviour compared to the more conventional correlation and regression analyses?

- With the exception of the size effect, the value effect and returns momentum none of the variables included in this study were studied in detail before on the JSE (to the best of our knowledge). Which of the explanatory variables included in this study can be proven to be associated with systematic anomalous stock return behaviour, in the process assisting on-going efforts to help explain observed stock return behaviour?

- Given that the size effect has long been recognised, are significant differences observed between different stock size categories regarding behaviour with respect to the other explanatory variables?

The outline of the rest of the paper is as follows: Section 2 provides a detailed literature review of historic studies performed on JSE data with respect to stock return anomalies; Section 3 describes the methodology followed for this work, including the definition of the considered set of explanatory variables and their statistical behaviour, as well as a description of the correlation, regression and sorted returns analyses that are applied to evaluate the ability of indicators to explain anomalous stock returns; Section 4 provides the empirical results obtained using these methods; and Section 5 provides a summary of the results and conclusions.

\section{LITERATURE REVIEW}

As indicated above most of the phenomena investigated in this paper have been widely researched on the larger financial markets. The focus of this study is to compare the behaviour of stock returns on the JSE with behaviours that were previously documented for other markets, more specifically the NYSE. This literature study therefore mostly focuses on research results previously reported for JSE listed stocks and on the relationship between stock returns and the set of explanatory variables considered in this paper.

Plaistowe and Knight (1986), using data for 35 firms covering the period 1973-1980, found that firms with low book-to-market $(\mathrm{B} / \mathrm{M})$ values tend to under-perform the market on a risk-adjusted basis, using the Sharpe market model, while firms with high $\mathrm{B} / \mathrm{M}$ tend to outperform the market. The work of Fraser and Page (2000) demonstrated that both $\mathrm{B} / \mathrm{M}$ and stock return momentum independently have the ability to predict stock returns one month into the future to earn superior returns. Graham and Uliana (2001) found evidence of the value-growth phenomenon on the JSE, and more specifically that for the period 1992-1996 value stocks (with high $\mathrm{B} / \mathrm{M}$ ) outperform growth stocks (with low B/M). In contract to these results Robins, Sandler and Durand (1999) demonstrated that over the period November 1985 to November 1994 portfolios consisting either of stocks with below median market capitalisation or of stocks with above median $\mathrm{B} / \mathrm{M}$ did achieve excess returns compared to the rest of the market, but that these excess returns were not statistically significant after compensating for risk, a result which is in support of the EMH.

Van Rensburg and Robertson (2003) found not only that small size earns a higher return on the JSE, but that firms with smaller size also has smaller beta compared to larger firms, and that the same is true for stocks with low price-to earnings ratios $(\mathrm{P} / \mathrm{E})$, evidence that is directly in contradiction of both the CAPM and $\mathrm{EMH}$. Auret and Sinclaire (2006) found that B/M can be used to predict subsequent higher stock returns, and that $B / M$ subsumes the effect of size and $P / E$. These results were largely confirmed by Basiewicz and Auret (2009), who found that both the size and value effects persisted after providing for transaction costs. They however concluded that the value premium is lower than what earlier research on the JSE has shown, and that these differences may be explained by illiquidity and the absence of testing for transaction costs.

In a study that included a larger number of explanatory variables, covering the period 1977 to 1994 , Klerck and Maritz (1997) investigated the application of Graham's stock selection criteria. They found that a 
number of fundamental parameters, including the P/E ratio, dividend yield, book-to-market equity, market capitalization versus net asset value, debt-versus-book equity, current ratio and earnings growth rate, provides risk adjusted returns higher than predicted by the CAPM.

Bhana (2007) reported that stocks announcing the repurchasing of shares on average display positive returns around the repurchase announcement, and that this phenomenon is more significant for stocks repurchasing $10 \%$ of more of shares versus stocks that repurchases less than $2,5 \%$ of shares. Furthermore he found that smaller companies display a more significant positive reaction to share repurchases for the period 20 days before and after the repurchase announcement (almost 10\% for the two smallest deciles) compared to larger companies (approximately 2,5\% for the two largest deciles). This study examines the same phenomenon through the inclusion of the net shares issued (NS) explanatory variable; if the same behaviour is observed it could be expected that stock returns should be negatively correlated with NS (as negative NS implies the repurchasing of shares while positive NS describes the opposite behaviour from companies, i.e. issuing more shares). It will furthermore be interesting to note the significance of NS for the different stock size categories Big, Small and Micro in comparison with the results of Bhana (2007).

In yet another study Bhana (2008) found that there is a positive market reaction to announcements of new capital expenditures, and that this effect was more pronounced for focussed firms compared to diversified firms. Our study investigates a similar effect by including asset growth into the list of explanatory variables. While the study of Bhana (2008) measured the effect that is observed in the period around the announcement date our study measures the longer term effect that is observed over the subsequent 12 month period. It would therefore be interesting to determine whether the immediate positive effect was followed by subsequent superior stock returns, whether the initial excess return fully reflected the positive impact of capital expenditure on future returns, or on the contrary if such announcements leading to asset growth possibly resulted in lower subsequent returns, indicating an initial overreaction from the market.

A related area for research addresses the type of techniques to use in order to model the relationships that may be uncovered between future stock returns and any number of explanatory variables. Within the South African context a relevant study was performed by Basiewicz and Auret (2010), who replicated an earlier study by Fama and French (1993). The latter authors developed a three factor model to explain stock returns in terms of the size effect, the value effect and a so-called market effect. Basiewicz and
Auret (2010) found support for the ability of this three factor linear regression model to explain stock returns on the JSE, as the book-to-market value ratio could not explain the pricing errors of these models. The size effect however could not be completely extinguished from the pricing errors - this was attributed to market microstructure effects, a phenomenon that was previously identified by Acharya and Pederson (2005) and by Stoll and Whaley (1983).

Our study will also investigate the value-growth phenomenon, as book-to-market is one of the explanatory variables included in our study. In contrast to the prior studies we include the complete set of listed shares (numbering about 376 by the end of 2010) and cover a much longer period (1985 to 2010); we would therefore expect to achieve results that are more representative of behaviour on the JSE as a whole.

\section{RESEARCH METHODOLOGY}

For the purpose of direct comparison this paper follows as far as practically possible the same methodology as that of Fama and French (2008), including the use of cross-section regression analysis as well as the calculation of sorted returns for shares ranked in terms of the respective explanatory variables. In addition we also perform both time-series and cross-sectional correlation analyses in order to verify if consistent results are obtained regarding the relationships between stock returns and the set of explanatory variables. We apply a number of widely used risk measures to sorted stock returns in order to verify if the anomalous returns that are obtained can be explained in terms of the risk profiles of the respective stock categories. We extend the sorted returns analysis to different stock size categories to ascertain whether the set of explanatory variables retains their explanatory power within each of the respective size categories.

For each relationship that is investigated the null hypothesis is derived from the efficient market hypothesis, i.e. that there should be no systematic and statistically significant relationship between future returns and the historic value of any of the explanatory variables used, as the information used is publicly available. Any such relationship that is detected can therefore be viewed as an anomaly that provides evidence against the efficient market hypothesis; such evidence against EMH will be strengthened if an anomalous relationship can be confirmed using different techniques. In this paper we use three different techniques to achieve this objective: time series and cross-sectional correlations, cross-section regressions, and sorted returns.

It is recognised that several of the anomalies that are investigated in this study have been reliably identified before through prior studies as referred to in the 
literature review. The approach that we follow is hence not only to test for the validity of each respective null hypothesis, but more specifically to determine to what extent the relationships that are observed are aligned with those identified through previous research work.

\subsection{Data used}

While this study was mainly designed to allow direct comparison with the results of Fama and French (2008), it will also be instructive to compare results where relevant with those of previous studies performed on the JSE. Several of those studies were limited to relatively short time periods, e.g. Plaistowe and Knight (1986) covered only a 7-year time period, Graham and Uliana (2001) a period of only four to five years, Robins et al. (1999) a period of nine years and Van Rensburg and Robertson (2003) a ten year period ending in 2000. Our results will indicate if similar behaviour is detected when using data covering a substantially longer time period. Fraser and Page (2000) covered a much longer time period of about 24 years, but as their data set ended in 1997, it would be interesting to determine if stock return behaviour since that time changed significantly.

The data used was obtained from the databank operated by McGregorBFA; data was extracted for the period April 1985 to December 2010, i.e. for a period of almost 26 years. Survivorship bias was largely eliminated by including all shares that became delisted during the time period January 1990 to December 2010. By including these delisted shares the total number of shares considered in this study was hence increased from 376 (the number still listed by the end of the study period) to a total of 1316 , the majority of which were delisted prior to December 2010. Stocks that were delisted during this period were retained in the set for subsequent periods but the respective prices of the stocks were allocated zero values as from the time of delisting.

As this study aims to identify and analyse systematic relationships between stock returns and fundamental explanatory variables as observed over time, it was decided to also exclude those stocks that were listed for such a short period of time that no systematic behaviour could be observed during the period of listing. By using a minimum listing period of 24 months (in order to include at least 2 sets of financial results for each firm), as well as eliminating those stocks that never published any set of financial results, the total number of stocks considered was reduced from 1316 to 1 023. This still represents a larger stock universe studied over a longer period of time compared to any previously published study of this nature for JSE stocks.

The number of stocks forming part of the available JSE stock universe at any specific point in time and with a minimum listing period of 24 months varied from only 18 stocks in April 1985 to 90 shares in April 1990, 487 in April 1995, 518 shares in April 2000, 343 in April 2005 and 369 shares by April 2010. In order to further reduce the impact of survivorship bias the analysis only started at the point in time when there were at least 50 stocks available in the data set, which occurred by April 1988. The analysis was hence effectively applied to between 22 and 23 years of data and to a larger stock universe compared to any of the previous JSE studies focusing on anomaly returns.

Price data was extracted on a monthly basis to allow the calculation of monthly returns, as this was the time base used in all returns calculations. In addition the biannual dividend declarations and annual financial statements were extracted to allow the calculation of the list of explanatory variables as described in the next section. In the majority of cases the McGregorBFA data has been compensated for the effect of stock splits; dividend yield data was however used to verify if reported dividend data for each 12 month period could be reconciled with adjusted share pricing - in some cases dividend data had to be adjusted upwards or downwards by a factor as derived from share price and dividend yield figures.

More or less in line with the approach followed by Fama and French (FF) we create Micro, Small and Big stock categories by using the ranking of stocks in terms of market capitalization: Micro stocks are defined as those stocks making up the first $3 \%$ of total market capitalisation, Small stock are those stocks making up the next $10 \%$ with Big stocks making up the remaining $87 \%$ of overall market capitalisation. The regression and sorted returns analyses were repeated for each of these size categories to determine if the relationships between stock returns and the explanatory variables are consistent across size groups.

\subsection{Defining the indicators}

A primary focus of this paper is to determine if a list of explanatory variables that have been shown to be associated with anomalous returns on the NYSE possess similar abilities for stocks on the JSE. The same fundamental information regarding stock behaviour can be reflected by different combinations of related indicators, including $P / E, B / M, Y / B$ and others. For the sake of direct comparison we decided to investigate the same set of variables used by FF in most of their reported research; of these variables six are strictly fundamental indicators while the seventh (Momentum of returns) can be viewed as a mixture of fundamental and technical indicators, as it is based on past pricing as well as historic dividends. 
The list of parameters that were evaluated to determine their ability to predict anomalous future stock returns were hence as follows:

1. Market capitalization (MC), defined as the natural logarithm of the stock price multiplied by the current number of issued shares.

2. Book-to-market $(B / M)$, defined as the ratio of the book value of equity per share to the market value of a share.

3. Net share issues (NS), defined as the logarithm of the ratio between the current number of shares issued by the company and the number of shares issued 12 months ago.

4. Yield-to-book (Y/B), defined as the earnings yield per share divided by the book value per share.

5. Accruals, defined as the proportional increase of operating assets over the past 12 months.

6. Change in Assets $(\mathrm{d} A / \mathrm{A})$, defined as the proportional increase in total assets over the past 12 months.

7. Momentum, defined as the return of the stock over the period from 12 months to 1 month prior to the current date, and expressed as a percentage.

\subsection{Correlation analysis applied to explanatory variables}

As a first step to unravel the relationships between our set of indicators and anomalous returns we calculate the linear correlations between each indicator and two versions of future stock returns: firstly the one month future returns Ret1 p1 and the twelve months future return Ret12_p12. Returns were calculated using the change in the baseline value of each stock, with the baseline value being the value referred to the initial date when the stock was first listed, and including the impact of dividend pay-outs. It was assumed that dividends are re-invested into the same share - the impact of this re-investment was calculated in terms of a dividend factor that will be one in months when no dividends are paid out but larger than one in months with pay-outs:

DivFactor $_{i, j}=$ DivFactor $_{i, j-1} \times\left(1+\frac{\text { Div }_{i, j}}{\text { Price }_{i, j}}\right)$

with $\operatorname{Div}_{i, j}$ the dividend and Price ${ }_{i, j}$ the price of share $i$ for month $\mathrm{j}$. The effective value of the share that is held including the positive impact of dividends is calculated as follows:
ShEffVal $_{i, j}=$ Price $_{i, j} \times$ DivFactor $_{i, j}$

Finally the one month return of the i-th share realised by the end of month $j+1$ is calculated as the relative change in share baseline value during the respective period using the following formulae for the future returns:

Ret1_p1 $1_{i, j+1}=\frac{\operatorname{ShEffVal}_{i, j+1}-\operatorname{ShEffVal}_{i, j}}{\operatorname{ShEffVal}_{i, j}}$

whereas the 12 month return by the end of month $j+12$ is given by

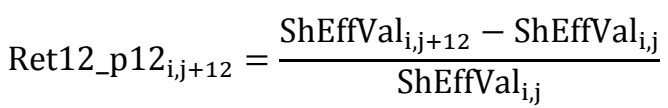

It is important to differentiate between the two types of correlation that can be calculated. The time based correlation calculates the correlation between changes in stock return and changes in an explanatory variable over time. This calculation is repeated per stock and after each consecutive time period. In this case no additional time lags between variables were considered: at each point in time the historic value for the explanatory variable and the future value for return as from that period one month (or twelve months) into the future was used as input to the correlation calculation. To obtain a summary measure representative of the entire population at each time period the average of the time-based correlations was taken for all stocks. This calculation is repeated after each period once new data has been added to the available data set. This correlation parameter measures the ability of an explanatory variable to predict the future return for stocks; it however does not directly measure the extent to which differences in the value of the explanatory variable between stocks is correlated with differences in future returns.

The alternative correlation measure, which is generally called the cross-sectional correlation, does exactly that: it is calculated by correlating, for each time period, the stock return differences between different stocks with the differences in values of the explanatory variable over the same set of stocks. This crosssectional correlation is also calculated after each period and the average of all cross-sectional correlations is taken over the entire period for which data is available. As this correlation parameter directly measures the ability of an explanatory variable to predict differential future returns of the stocks, it could be expected that it would be a superior indicator based on which to select stocks that will on average outperform the market for the prediction period.

As is the case with most statistical modelling exercises, there is no guarantee that a relationship that exists over a specific period of time will persist during subsequent periods. For this reason the standard 
deviations of the correlation coefficients over time are also calculated for both correlation measures, to indicate how stable these measures are to detect relationships that can be exploited over extended time periods.

\subsection{Performing cross-section regression analysis based on indicators}

The extraction of a linear regression model would be the logical next step when trying to combine the predictive capabilities of the above set of indicators. Not only could the regression model potentially improve on the predictive abilities of any one indicator when used in isolation, but the sign and values of the regression coefficients, as well as the confidence levels by which these coefficients are extracted from the data set will provide a valuable indication of the strength and statistical significance of the relationships between indicator and future returns.

For this purpose a linear cross-section regression model was extracted that models 12 month future returns (i.e. the variable Ret12_p12 as defined above) in terms of the set of indicators that were available for each share at the end of the month before the start of this 12 month period. 12 month returns were preferred over 1 month returns, as the above correlation analysis indicated that more significant relationships exist between the set of indicators and this measure for future returns. This would furthermore allow direct comparison with the results of Fama and French (2008), who also used 12 month returns for their crosssection regression analysis. The exercise was repeated after each month, starting the analysis at the point in time where there were at least 50 stocks listed on the JSE (in this case it was April 1988) and available in the data set, and repeating this exercise up to December 2010. In each case the value of the linear regression coefficients as well as the lower and upper confidence levels for these coefficients were extracted for the data set available at that point in time. By calculating the mean and standard deviation of the time series of regression coefficients that were extracted over the entire time period of 273 months it was also possible to calculate the t-statistics for each regression coefficient; this provided a more reliable indication of the statistical significance of the potential relationships that were uncovered.

An obvious question to address when performing a regression analysis is: which explanatory variables should be included in the regression model? The answer to this is not straightforward, as the presence of specific variables in the model will impact upon the regression coefficient obtained for other variables that are included. As the relationships of $\mathrm{MC}$ and $\mathrm{B} / \mathrm{M}$ with future returns have already been well-established through earlier research, and as these were confirmed by the correlation analysis in the previous section, the issue is really whether to include $\mathrm{MC}$ and $\mathrm{B} / \mathrm{M}$ into the regression model or not. On the one hand the presence of $\mathrm{MC}$ and $\mathrm{B} / \mathrm{M}$ may obscure the relationship between future returns and a less dominant explanatory variable being investigated. On the other hand it will be useful to investigate the significance of the regression coefficient for a such a new variable in the presence of $\mathrm{MC}$ and $\mathrm{B} / \mathrm{M}$, as it will provide an indication of the marginal ability of such a variable to help explain future returns over and above the already known relationships with $\mathrm{MC}$ and $\mathrm{B} / \mathrm{M}$.

Against this background it was decided to perform a dual cross-section regression analysis: for the first run both $\mathrm{MC}$ and $\mathrm{B} / \mathrm{M}$ are included in the regression model and the resulting regression coefficients of the additional variables are interpreted as indicative of the marginal abilities of those variables to help explain future returns. The regression analysis was then repeated in the absence of $\mathrm{MC}$ and $\mathrm{B} / \mathrm{M}$, providing an indication of the independent ability of the additional variables to explain future returns.

\subsection{Evaluating predictors based on sorted returns}

While both the correlation and regression analyses could be expected to provide a good indication of the general relationships that exist between future returns and our set of indicators, neither of these techniques directly indicates which parameters will be the most effective to use when compiling portfolios that are expected to outperform the market. As discussed before, such a portfolio will tend to consist of shares that display extreme behaviour with respect to the indicators used for stock selection. Should the relationship between future returns and the respective indicator(s) be non-linear, the comparative ability of the indicators to identify an optimal set of stocks may not be exactly in line either with the linear correlations that are observed or with the results of a linear regression analysis.

Using the same approach as described in Fama and French (2008), the ability of each of the identified indicators to explain cross-sectional differences in returns between different stocks is investigated as follows:

For each of the explanatory variables in succession all stocks are ranked based on the value of the respective parameter for each individual stock (e.g. the first sort is done based on MC for each stock; next a sort is done based on $\mathrm{B} / \mathrm{M}$, etc.). Once a ranking has been done, the stocks are divided into five sorted categories, each containing the same number of stocks, from the lowest to the highest values for the respective sorting parameter.

The aggregate 1 month return for the month following directly after the implementation of the sort is then 
calculated, using the 1 month returns of all stocks within each sorted category. This was repeated using both equally weighted as well as value weighted (i.e. based on market capitalization) formulae for aggregate returns:

EqW_Ret $=\frac{1}{N} \sum_{n=1}^{N} \operatorname{Ret}(n)$

ValW_Ret $=\frac{\sum_{\mathrm{n}=1}^{\mathrm{N}} \operatorname{Ret}(\mathrm{n}) \operatorname{MarketCap}(\mathrm{n})}{\sum_{\mathrm{n}=1}^{\mathrm{N}} \operatorname{MarketCap}(\mathrm{n})}$

where $\operatorname{Ret}(\mathrm{n})$ is the return of the $\mathrm{n}$-th stock, MarketCap $(n)$ is the market capitalization of the $n$-th stock at that point in time, and $\mathrm{N}$ is the total number of stocks in the portfolio under consideration.

This process is repeated after each month, in every case only using explanatory variable information that was already available before the start of the month.

The average returns of the sorted categories are calculated over the period up to that point in time:

$\operatorname{AvRet}\left(\mathrm{i}_{\text {cat }}\right)=\frac{1}{\mathrm{M}_{\mathrm{i}}} \sum_{\mathrm{m}_{\mathrm{i}}=1}^{\mathrm{M}_{\mathrm{i}}} \operatorname{Ret}\left(\mathrm{m}_{\mathrm{i}}\right)$

where $M_{i}$ is the number of months over which the average return is calculated, $\mathrm{i}_{\text {cat }}$ is the $\mathrm{i}$-th sorted category for which the return is calculated, and $\operatorname{Ret}\left(\mathrm{m}_{\mathrm{i}}\right)$ is either the equal weighted or the value weighted average return of all stocks falling into that category.

Subsequently the difference between returns of the lowest and highest sorted categories is determined:

$\operatorname{AvRet}_{\text {High-Low }}=\operatorname{AvRet}\left(\mathrm{i}_{\text {max }}\right)-\operatorname{AvRet}\left(\mathrm{i}_{\text {min }}\right)$

In FF these are called the hedged portfolio returns, as a hedging strategy will typically involve going long in those stocks that are predicted to display the highest future returns and going short in the stocks expected to display the lowest future returns.

After completing the above exercise for all months included in the period under investigation the tstatistics of the sorted category portfolio returns are calculated. This will indicate if the returns of the sorted stock categories differ significantly from the return of the overall population of stocks. The formula used for the t-statistic is as follows:

$\mathrm{t}-\mathrm{stat}=\frac{\mu(\text { sorted category })-\mu(\text { population })}{\sigma(\text { sorted category }) / \sqrt{\mathrm{N}}}$ where $\mu$ (sorted category) is the average return for the respective sorted category calculated over the entire time period, $\mu$ (population) is the population average return over the same time period, $\sigma$ (sorted category) is the standard deviation of the sorted category and $\mathrm{N}$ is the number of time periods over which the consecutive sorts were implemented, i.e. the sample size.

Given that the dependence of stock returns on MC and $\mathrm{B} / \mathrm{M}$ has already been well established in earlier literature as described in section 1, and confirmed through the correlation and regression analyses of sections 3 and 4, it will be of interest to know if the other less studied explanatory variables have any marginal ability to predict stock returns, after removing the impact of $\mathrm{MC}$ and $\mathrm{B} / \mathrm{M}$. To investigate this aspect we once again follow the FF methodology: all stocks are divided into 25 sorted categories along two sorted dimensions, one for $\mathrm{MC}$ and one for $\mathrm{B} / \mathrm{M}$ (in FF these are called 'matching portfolios'). Each stock hence falls within a category that it shares with other stocks that fall in the same category based on their $M C$ and $B / M$ values. The value weighted average return is calculated for each of the 25 matching portfolios and for each period, and this matching portfolio weighted average return is subtracted from the nominal return for each stock falling in that category, to produce a net return for each stock and for each period:

$\operatorname{RetNet}_{i, j}=\operatorname{Ret}_{i, j}-\operatorname{RetMP}_{n, j}$

with $\operatorname{Ret}_{i, j}$ and $\operatorname{RetNet}_{i, j}$ the nominal and net return respectively of the i-th stock for the j-th period, and RetMP $_{n, j}$ the nominal ValW average return of the $n$-th matching portfolio to which the i-th stock belong during that period. The behaviour of the net returns for the explanatory variables other than $M C$ and $B / M$ will be compared with the behaviour observed for their nominal returns to determine if any relationship with future returns remains after compensating for the effect of $\mathrm{MC}$ and $\mathrm{B} / \mathrm{M}$.

To allow a comparison of the returns across the sorted categories on a risk-adjusted basis we also calculate the Sharpe and Treynor performance measures for each sorted category, using the following formulae for the i-th sorted category:

SharpePM $_{\mathrm{i}}=\frac{\text { AvRet }_{\mathrm{i}}-\text { Ret }_{\mathrm{RF}}}{\text { StdRet }_{\mathrm{i}}}$
TreynorPM $_{\mathrm{i}}=\frac{\text { AvRet }_{\mathrm{i}}-\text { Ret }_{\mathrm{RF}}}{\beta_{\mathrm{i}}}$

with AvRet $_{i}$ the average return, StdRet the standard deviation of return and $\beta_{i}$ the market beta for the $i$-th category and Ret $_{\mathrm{RF}}$ the risk free rate of return. 


\section{EMPIRICAL RESULTS}

The results that were obtained were compared at three levels: firstly the results of the time-series correlations, cross-sectional correlations, regression analysis and sorted returns analysis are compared against each other to determine if the relationships that are identified using different techniques are consistent with each other. Secondly the results are compared with those of Fama and French (2008) to determine if stock behaviour on the JSE is similar to stock behaviour on the NYSE. Thirdly results are compared, as far as possible, with results previously obtained on the JSE through the studies referenced in the literature review.

\subsection{Statistical behaviour of the explanatory variables}

Before commencing with the evaluation of the explanatory ability of the above set of indicators, it would be interesting to review the statistical behaviour of the explanatory variables themselves. It is not deemed to be sufficient to only calculate the mean and standard deviation for each variable, as this may not be representative of the spread of behaviour that is observed across the total population of stocks. Against the background that stock selection strategies aimed at maximising returns often result in the selection of stocks with extreme behaviour in some respect, rather than stocks that represent average behaviour of the population, we rank the stocks in terms of their values for each of the above indicators, and then sort them into categories based on rank (in order to allow direct comparison with the results of FF we also use 5 sorted categories in each case).

The means per sorted category for each indicator are displayed in Table 1. As it is known from previous studies that MC has a substantial impact on stock behaviour, these statistics were calculated for the market as a whole, as well as for Micro, Small and Big stocks separately.

When studying the statistical behaviour of the explanatory variables a few comments are in order given the subsequent analysis that will be performed to evaluate their ability to select stocks with abnormal return potential. The parameter statistics reflected in Table 1 are calculated on an equally weighted basis (i.e. each stock carries the same weight when contributing towards a statistical measure). As Micro stocks far outnumber both Small and Big stocks, their impact on the calculated statistics is highly emphasized.

Furthermore it can be seen that Micro stocks in general display more extreme behaviour compared to Small or Big stocks (e.g. comparing the average values of the two extreme categories for $\mathrm{B} / \mathrm{M}$ and observing those values for Micro, Small and Big stocks - the former clearly displays much larger extremes than the latter two). This will have a dual impact when using sorted returns as basis for predicting abnormal stock returns: not only will Micro stocks tend to be overrepresented in the extreme sorted categories, but the values displayed by the Micro stocks in those categories will tend to be more extreme than the values of stocks from other size categories.

This does not however disqualify sorted returns as basis for evaluating the ability of these indicators to select abnormally performing stocks, as the exact same phenomena (over-representation of Micro stocks in some types of portfolios) will tend to occur when compiling portfolios aimed at maximising returns. The use of the sorted returns method will help to disclose to the prospective investor the extent to which a proposed strategy will be impacted by extreme stock behaviour, and more specifically the degree to which such a strategy will rely on Micro stocks to achieve its return objectives - an important consideration, given the limited degree to which large portfolios can invest into Micro stocks.

\subsection{Correlation analysis applied to explanatory variables}

The averages and standard deviations for both timeseries and cross-sectional correlations between explanatory variables and future returns are displayed in Table 2, for each of the explanatory variables as defined in the previous section. We also include the mutual correlations amongst the respective explanatory variables. To allow comparative assessment of the stability of both correlation measures a column is added to display the average correlation coefficient normalised with respect to standard deviation of the correlation coefficient over time.

Firstly we compare the nature of the relationship between the explanatory variables and future stock returns as reflected in Table 2 with relationships identified in earlier JSE studies. MC has a consistent negative relationship with future returns, which is consistent with the earlier reports of Klerck and Maritz (1997), Van Rensburg and Robertson (2003) and of Basiewicz and Auret (2009) on the size effect. This phenomenon is slightly more significant for crosssectional than for time-series correlations, which could be expected, as the change in MC over time for most shares is much smaller compared to cross-sectional differences in MC. 
Table 1: Sorted category averages of explanatory variables for stock size categories All, Micro, Small and Big

\begin{tabular}{|c|c|c|c|c|c|c|}
\hline \multirow[t]{2}{*}{ Explanatory Variable } & \multirow[t]{2}{*}{ Size } & \multicolumn{5}{|c|}{ Categories } \\
\hline & & 1 & 2 & 3 & 4 & 5 \\
\hline \multirow{4}{*}{ MC } & All & $-7,15$ & $-5,13$ & $-3,74$ & $-2,39$ & $-0,34$ \\
\hline & Micro & $-7,66$ & $-5,99$ & $-4,98$ & $-4,07$ & $-3,20$ \\
\hline & Small & $-2,62$ & $-2,34$ & $-2,06$ & $-1,76$ & $-1,37$ \\
\hline & Big & $-1,00$ & $-0,65$ & $-0,15$ & 0,43 & 1,44 \\
\hline \multirow{4}{*}{ Momentum } & All & $-58,16$ & $-29,69$ & $-11,61$ & 8,61 & 107,71 \\
\hline & Micro & $-63,50$ & $-35,52$ & $-16,26$ & 6,23 & 128,09 \\
\hline & Small & $-44,07$ & $-20,67$ & $-6,09$ & 11,27 & 71,91 \\
\hline & Big & $-39,55$ & $-18,10$ & $-5,31$ & 9,36 & 51,50 \\
\hline \multirow{4}{*}{$\mathrm{B} / \mathrm{M}$} & All & $-4,31$ & 0,15 & 0,45 & 0,94 & 12,94 \\
\hline & Micro & $-7,01$ & 0,15 & 0,59 & 1,27 & 18,42 \\
\hline & Small & $-0,10$ & 0,19 & 0,38 & 0,65 & 1,52 \\
\hline & Big & $-0,03$ & 0,12 & 0,27 & 0,43 & 0,92 \\
\hline \multirow{4}{*}{ NS } & All & $-0,069$ & 0,000 & 0,000 & 0,013 & 0,422 \\
\hline & Micro & $-0,089$ & 0,000 & 0,000 & 0,007 & 0,365 \\
\hline & Small & $-0,028$ & 0,000 & 0,002 & 0,022 & 0,412 \\
\hline & $\mathrm{Big}$ & $-0,035$ & 0,000 & 0,005 & 0,023 & 0,520 \\
\hline \multirow{4}{*}{ Y/B } & All & $-256,0$ & 4,2 & 18,4 & 34,3 & 312,7 \\
\hline & Micro & $-328,7$ & 1,0 & 13,1 & 30,0 & 359,5 \\
\hline & Small & $-95,9$ & 10,8 & 23,9 & 37,4 & 143,1 \\
\hline & Big & $-134,9$ & 15,4 & 26,8 & 39,7 & 265,0 \\
\hline \multirow{4}{*}{ Accr } & All & $-658,9$ & $-2,8$ & 6,6 & 31,4 & 615,7 \\
\hline & Micro & $-804,7$ & $-4,0$ & 4,7 & 30,7 & 690,9 \\
\hline & Small & $-390,6$ & $-1,0$ & 10,1 & 30,6 & 387,8 \\
\hline & Big & $-361,0$ & $-3,2$ & 8,9 & 28,8 & 679,1 \\
\hline \multirow{4}{*}{$\mathrm{dA} / \mathrm{A}$} & All & $-1,88$ & 0,00 & 0,00 & 0,00 & 2,74 \\
\hline & Micro & $-0,83$ & 0,00 & 0,00 & 0,00 & 0,36 \\
\hline & Small & $-1,21$ & 0,00 & 0,00 & 0,00 & 4,41 \\
\hline & Big & $-7,39$ & 0,00 & 0,00 & 0,00 & 9,62 \\
\hline
\end{tabular}

Table 2: Time-based and cross-sectional correlations between different indicators and between indicators and future returns

\begin{tabular}{|c|c|c|c|c|c|c|c|c|c|c|c|c|}
\hline \multirow[b]{2}{*}{ Parameters } & & \multirow[b]{2}{*}{ MC } & \multirow[b]{2}{*}{$\mathrm{B} / \mathrm{M}$} & \multirow[b]{2}{*}{ NS } & \multirow[b]{2}{*}{ Accr } & \multirow[b]{2}{*}{$\mathrm{dA} / \mathrm{A}$} & \multirow[b]{2}{*}{$\mathrm{Y} / \mathrm{B}$} & \multirow[b]{2}{*}{ Mom } & \multicolumn{2}{|c|}{ Cross-sectional } & \multicolumn{2}{|c|}{ Time based } \\
\hline & & & & & & & & & Ret1 & Ret12 & Ret1 & Ret12 \\
\hline \multirow[t]{3}{*}{ MC } & Ave & 1,00 & $-0,08$ & 0,08 & 0,00 & 0,06 & 0,02 & 0,07 & $-0,04$ & $-0,08$ & $-0,04$ & $-0,07$ \\
\hline & Std & 0,00 & 0,08 & 0,05 & 0,06 & 0,08 & 0,06 & 0,11 & 0,09 & 0,08 & 0,02 & 0,05 \\
\hline & Norm Ave & - & $-1,00$ & 1,63 & 0,06 & 0,78 & 0,34 & 0,66 & $-0,48$ & $-1,03$ & $-1,89$ & $-1,38$ \\
\hline \multirow[t]{3}{*}{$\mathrm{B} / \mathrm{M}$} & Ave & $-0,08$ & 1,00 & $-0,01$ & 0,00 & 0,00 & 0,00 & 0,02 & 0,01 & 0,00 & 0,02 & 0,05 \\
\hline & Std & 0,08 & 0,00 & 0,02 & 0,01 & 0,01 & 0,00 & 0,13 & 0,10 & 0,09 & 0,02 & 0,04 \\
\hline & Norm Ave & $-1,00$ & - & $-0,51$ & $-0,15$ & $-0,26$ & $-0,39$ & 0,14 & 0,07 & 0,00 & 1,17 & 1,34 \\
\hline \multirow[t]{3}{*}{ NS } & Ave & 0,08 & $-0,01$ & 1,00 & $-0,15$ & $-0,07$ & 0,00 & 0,05 & 0,01 & 0,00 & 0,01 & $-0,01$ \\
\hline & Std & 0,05 & 0,02 & 0,00 & 0,24 & 0,08 & 0,02 & 0,09 & 0,06 & 0,08 & 0,01 & 0,02 \\
\hline & Norm Ave & 1,63 & $-0,51$ & - & $-0,63$ & $-0,86$ & $-0,22$ & 0,62 & 0,10 & $-0,05$ & 1,34 & $-0,41$ \\
\hline \multirow[t]{3}{*}{ Accr } & Ave & 0,00 & 0,00 & $-0,15$ & 1,00 & 0,02 & 0,20 & 0,00 & 0,00 & 0,00 & 0,00 & 0,00 \\
\hline & Std & 0,06 & 0,01 & 0,24 & 0,00 & 0,03 & 0,34 & 0,04 & 0,06 & 0,07 & 0,01 & 0,02 \\
\hline & Norm Ave & 0,06 & $-0,15$ & $-0,63$ & - & 0,57 & 0,58 & 0,04 & $-0,03$ & $-0,02$ & 0,10 & 0,18 \\
\hline \multirow[t]{3}{*}{ dA/A } & Ave & 0,06 & 0,00 & $-0,07$ & 0,02 & 1,00 & $-0,01$ & 0,01 & 0,00 & 0,00 & 0,00 & 0,01 \\
\hline & Std & 0,08 & 0,01 & 0,08 & 0,03 & 0,00 & 0,04 & 0,04 & 0,04 & 0,04 & 0,00 & 0,01 \\
\hline & Norm Ave & 0,78 & $-0,26$ & $-0,86$ & 0,57 & - & $-0,14$ & 0,26 & 0,03 & $-0,12$ & 0,62 & 1,28 \\
\hline \multirow[t]{3}{*}{ Y/B } & Ave & 0,02 & 0,00 & 0,00 & 0,20 & $-0,01$ & 1,00 & 0,00 & $-0,01$ & 0,00 & $-0,01$ & 0,00 \\
\hline & Std & 0,06 & 0,00 & 0,02 & 0,34 & 0,04 & 0,00 & 0,04 & 0,06 & 0,07 & $-0,01$ & 0,03 \\
\hline & Norm Ave & 0,34 & $-0,39$ & $-0,22$ & 0,58 & $-0,14$ & - & $-0,05$ & $-0,11$ & $-0,05$ & $-0,23$ & $-0,03$ \\
\hline \multirow[t]{3}{*}{ Momentum } & Ave & 0,07 & 0,02 & 0,05 & 0,00 & 0,01 & 0,00 & 1,00 & 0,02 & 0,01 & 0,00 & 0,04 \\
\hline & Std & 0,11 & 0,13 & 0,09 & 0,04 & 0,04 & 0,04 & 0,00 & 0,09 & 0,07 & 0,02 & 0,05 \\
\hline & Norm Ave & 0,66 & 0,14 & 0,62 & 0,04 & 0,26 & $-0,05$ & - & 0,17 & 0,15 & 0,10 & 0,88 \\
\hline
\end{tabular}


The value effect as reported by Plaistowe and Knight (1986), Fraser and Page (2000) and Graham and Uliana (2001) is confirmed given the positive correlations between $\mathrm{B} / \mathrm{M}$ and future returns (for all but 12 month cross-sectional correlation that is very close to zero). In this case time-series correlations are somewhat larger than cross-sectional correlations, indicating that the value effect is not only present between different stocks, but also manifests itself for individual stocks as their respective $\mathrm{B} / \mathrm{M}$ values changes over time.

The negative correlation between NS and 12 month future stock returns confirms the earlier results of Bhana (2007) regarding the positive relationship between stock repurchases and subsequent returns, as NS will assume a negative value for stock repurchases. In this case the time-series correlation is double that of the cross-sectional correlation for 12 month returns, indicating that, compared to their own historic performances, stocks are specifically penalised subsequent to net stock issues and rewarded subsequent to stock repurchases.

Momentum displays a small but positive correlation with respect to future returns, indicating that recent good returns tend to persist over the subsequent 12 month period; the relatively weak correlations, and the fact that the 1 month cross-sectional correlations are similar in size compared to the 12 month crosssectional correlations is indicative that for many stocks the period of returns persistence may be less than 12 months. The fact that the cross-sectional correlations with 12 month returns are significantly smaller compared to the time-based correlations indicates that Momentum may be less useful for stock selection than what would have been anticipated based on the timebased correlations when viewed in isolation.

It can furthermore be observed that the relationships between the respective indicators and future returns vary substantially over time: for all of the indicators, with the exception of $\mathrm{MC}$ (for both correlation types) and $B / M$ and $d A / A$ (for time-based correlations), the normalised average correlations have absolute values that are substantially smaller than one. This indicates that $\mathrm{MC}$ should be the most consistent indicator for above average returns, which is in line with prior research (Fama and French, 2008), while the other indicators could be expected to possess less predictive power.

Comparing the columns for Ret1_p1 with those for Ret12_p12 it is clear that in most cases stronger correlations are obtained for 12 month future returns compared to 1 month future returns, even though Ret12_p12 predicts returns much further into the future than Ret1_p1. It would therefore appear that, while most of the correlations are relatively small, the correlations that are observed are fairly consistent over the 12 month prediction period, as the accumulation of the correlated behaviour tend to add up over time, while the same integration process has the effect of cancelling out some of the uncorrelated 'noise' factors that also impact returns, resulting in a net increase in correlation coefficients. One interesting exception to this phenomenon is Momentum, where the crosssectional correlation with Ret1_p1 is slightly larger than with Ret12_p12. As Momentum uses return information over the 12 months preceding the current point in time, this seem to imply that the majority of stocks do not maintain their return momentum over the full 24 month period over which the correlated parameters are calculated, possibly indicative of mean-reverting behaviour starting to occur.

Another noteworthy observation is that, while the timebased correlations are mostly smaller in magnitude compared to the cross-sectional correlations, in all cases but three (B/M and $d A / A$ for 12 month returns and Accr for both types of returns) the two types of correlation always have the same sign (i.e. both are either positive or negative), confirming that the relationships between future returns and the respective indicators that are uncovered seem to be consistent.

Should these indicators be used to build a multi-variate prediction model the correlations between the respective indicators would be of interest, as one would normally not include predictors that display a high degree of correlation with each other into the same model. The cross correlations were therefore calculated between all candidate predictors, as displayed in Table 2. As could be expected MC and $\mathrm{B} / \mathrm{M}$ are significantly negatively correlated (due to the fact that Market Capitalization per Share appears below the line in $\mathrm{B} / \mathrm{M}$ ) - care should therefore be taken regarding the inclusion of these two into a single model. Most other indicators display low levels of mutual correlation, and hence should not present any problem when being combined into the same model. The two notable exceptions are the strong negative correlations between NS and Accruals as well as between NS and $d A / A$. This would seem to indicate that companies issuing new shares are also experiencing deterioration in their asset base and therefore need additional share capital to balance this effect, which could help explain why the market in general reacts negatively to net share issues.

While the above linear correlations provide useful indications of predictive ability, it must be kept in mind that correlation reflects changes in parameter values across the entire range of values that each parameter may assume. Should these parameters be used as basis for stock selection, and assuming that any practical portfolio will only contain a small fraction of the total number of available stocks, the stocks to be selected are likely to be the ones displaying extreme behaviour with respect to those indicators that are the 
most strongly correlated (positively or negatively) with future returns. It could therefore be expected that extreme stock behaviour will be more relevant for the purpose of optimal stock selection than average behaviour over the entire range. This aspect is further investigated in the section on sorted stock returns.

\subsection{Cross-section regression analysis}

In this section we compare the results from the crosssection regression analysis with the correlation results, with the results of FF as well as, where relevant, with earlier JSE studies. Table 3 (a) displays the averages and standard deviations as well as the t-statistics for the regression coefficients that were obtained when including all seven of the explanatory variables previously investigated by FF (MC, B/M, Momentum, NS, Accr, $d A / A$ and $Y / B$ ). Results are provided for four stock categories: All, Big, Small and Micro.

As could be expected the regression coefficients in general are of the same sign as the corresponding correlation coefficients calculated in the previous section, confirming the general nature of the relationships between future returns and the respective indicators. It is furthermore clear that the indicators displaying stronger relationships with future returns in terms of correlations (notably $\mathrm{MC}, \mathrm{B} / \mathrm{M}$ and Momentum) also display more consistent relationships with future returns across different size groups, as well as more significant values for the t-statistic of the regression coefficients. Interesting differences are however observed between the different size groups.

In correspondence with the results of FF the regression coefficient for $M C$ is consistently negative across all size groups and with a high degree of significance (t-statistic varying between $-19,6$ for All to $-51,0$ for Big). Similarly consistent positive regression coefficients are observed for Momentum across all size groups, with t-statistics varying between 3,0 for Big and 14,0 for Micro stocks. The same holds true for $\mathrm{B} / \mathrm{M}$, with t-statistics varying between 5,6 for Big and 5,9 for Micro stocks.

An interesting result is obtained for Y/B: for the All, Small and Micro categories the regression coefficient is significantly positive, while for Big stocks it is significantly negative. It would therefore seem that the profitability of firms is not valued in the same way for firms falling into different size categories, a potential topic for future research.

The more significant results (notably those for $M C$, $\mathrm{B} / \mathrm{M}$, Momentum and $\mathrm{Y} / \mathrm{B}$ ) correspond with the results of FF, providing proof that stock behaviour on the JSE is in many respects similar to that observed on the NYSE. Differences with the results of FF are observed for the size of the t-statistics: for JSE All stocks the tstats for most of the explanatory variables are much larger than the already significant values that $\mathrm{FF}$ observed on the NYSE: MC $(-19,6$ vs $-4,36), B / M(7,3$ vs 3,77$)$, Momentum (11,9 vs 3,24$)$, Y/B (7,1 vs 3,19$)$, and Accr $(-9,7$ vs $-2,72)$, while for NS the negative $t-$ statistics is much smaller on the JSE compared to the NYSE. The only variables for which the sign of the tstatistic is reversed, compared both the FF and the correlation analysis, is NS $(13,6$ vs $-8,59)$ and $\mathrm{dA} / \mathrm{A}$ $(7,7$ vs $-7,37)$, but based on the correlation analysis these are also two of the weaker explanatory variables.

The possibility was investigated whether the few conflicting observations compared to the results of FF may have resulted from the presence of more prominent explanatory variables included into the same regression model with less prominent ones. In order to determine the impact of $\mathrm{MC}$ and $\mathrm{B} / \mathrm{M}$ on the regression coefficients for the remaining variables we investigate the regression coefficients that are obtained when including only NS, Momentum, Accr, $\mathrm{dA} / \mathrm{A}$ and $\mathrm{Y} / \mathrm{B}$ as explanatory variables. These results are displayed in Table 3(b).

It can be seen that, when $M C$ and $B / M$ are excluded from the model, the t-statistic for NS becomes less positive for All and Big stocks and turns negative for Small and Micro stocks, compared to the 7 factor model. This is however still significantly different from the results of FF, where significantly negative results were obtained for all size groups. This anomaly will be further investigated in section 4.4 below when we discuss sorted returns.

Similarly in the case of $d A / A$ the 5 factor regression model reduces the positive regression coefficients obtained above for the 7 factor model regression coefficient for all size categories; for all stock categories the sign of the regression coefficient, however, remains positive, which is in contrast with the results of FF.

It is important to determine which of the observed relationships are pervasive across all size groups and which relationships are limited to specific size categories. For this purpose regression models were extracted for each size group (Big, Small and Micro) separately. These results also appear in Tables 3 (a) and (b). The following observations can be made:

- The size effect as represented by $M C$ is maintained across all size groups, with t-statistics of the mean values for the $M C$ regression coefficient exceeding the requirements for statistical significance at the $1 \%$ level.

- $\quad \mathrm{B} / \mathrm{M}$ has a positive t-statistic for the Big and Micro size groups but is negative for Small stocks. This would appear to be an anomaly resulting from the multiple regression estimation process, as the 
correlation coefficients between $\mathrm{B} / \mathrm{M}$ and returns are positive for all size groups (this was confirmed by extracting a regression model on Small stocks using $\mathrm{B} / \mathrm{M}$ as the only regression variable - in that case the regression coefficient was strongly positive with a t-statistic of 25,8). The result for Small stocks is also in contrast with the results of FF where the t-statistic was positive across all size groups; smallest for the Big category and more significant for both Small and Micro.

- Momentum is significant across all size groups but strongest in Micro $(14,0)$ and weakest in Big $(3,0)$. When changing from the 7 factor to the 5 factor model the t-statistic for both Small and Big however increases $(18,6$ vs 11,8 and 6,8 vs 3,0$)$. This variation of Momentum across size groups differs from the result of FF for NYSE stocks, where Momentum was strongest in the Small and weakest in the Micro group.

- In the case of NS conflicting results are obtained for different size groups when observing the regression coefficients for the 5 factor models: while the t-statistics is positive for Big stocks, it becomes negative for Small and Micro stocks.

- For Accr a similar situation is observed: while for All and Micro stocks the t-statistic is negative in both cases, this is reversed for Big and Small stocks with significantly positive t-statistics irrespective of whether $\mathrm{MC}$ and $\mathrm{B} / \mathrm{M}$ are included in the model or not. It would therefore appear that Big and Small stocks are awarded for accumulating operational assets, while Micro stocks are penalised.

- In the case of $d A / A$ (which represent total asset growth) both Big and Small stocks display a positive but Micro a negative relationship with returns whether $\mathrm{MC}$ and $\mathrm{B} / \mathrm{M}$ are included or not. This corresponds to the positive correlation coefficients of the previous section, but differs from the consistently negative regression coefficients obtained by FF. It would therefore appear that on the JSE stocks are not in general penalised for growing assets.

- Lastly in the case of $Y / B$ the relationship with future returns are positive for All, Small and Micro but negative for Big stocks (although insignificantly so), where we get the curious result that stocks are punished for showing higher earnings yields as fraction of book equity ( $\mathrm{t}$ statistics of $-0,9$ and $-1,7$ in the absence and presence of $M C$ and $B / M$ respectively). This is also in conflict with the results of $F F$, where $Y / B$ had a consistently (although statistically insignificant) positive relationship with future returns across all size categories.

It was not possible to directly compare the above results for the size groups with any earlier results reported for JSE stocks, as none of the previous studies included a similar breakdown of stocks into size groups. The degree to which the explanatory power of the respective variables is retained (or not) across size groups can therefore be seen as one of the unique contributions of this paper.

In general it can be stated that with respect to $M C$, $\mathrm{B} / \mathrm{M}$, Momentum and $\mathrm{Y} / \mathrm{B}$ the regression analysis corroborates the results from the correlation analysis as well as those from earlier studies: all of these indicators display statistically significant relationships with 12 month ahead returns and the sign of the relationships seem to be stable across different stock size categories (with the exception of B/M for Small and $Y / B$ for Big stocks). For the other indicators the results are less clear: not only are the regression coefficients in general less significant in value, but also the different size groups are observed to display different types of behaviour with respect to these explanatory variables.

Further insights can be derived from the regression analysis by investigating the regression residuals resulting from the above exercise. The regression residuals are obtained by subtracting actual returns from modelled returns. If the relationships between future returns and the respective indicators are close to linear, one would expect the residuals to randomly vary in a more or less uniform pattern across the entire range of indicator values. Should that however not be the case, one can expect to observe a specific pattern present in the residuals that may be indicative of a more complex underlying relationship than assumed by the linear regression analysis.

In order to investigate this possibility the residuals obtained from the regression analysis were sorted in terms of the values of each of the explanatory variables used in the regression. Within each sorted category and for each explanatory variable (for the purpose of direct comparison with the results of FF we also used 5 sorted categories) the average value and standard deviation of the regression residuals as well as the t-statistic of the average were calculated. These results are displayed in Table 4. 
Table 3: Statistics of the regression coefficients obtained when modelling future 12 month returns as linear regression model of indicators

(a) Seven parameter regression model

\begin{tabular}{|c|c|c|c|c|c|c|c|c|}
\hline Size Group & Stat Par & MC & $\mathrm{B} / \mathrm{M}$ & NS & Mom & Accr & dA/A & Y/B \\
\hline All & $\begin{array}{l}\text { Ave } \\
\text { Std } \\
\text { t-stat }\end{array}$ & $\begin{array}{r}-1,08 \mathrm{E}-02 \\
8,18 \mathrm{E}-03 \\
-19,6 \\
\end{array}$ & $\begin{array}{r}1,40 \mathrm{E}-03 \\
2,85 \mathrm{E}-03 \\
7,3 \\
\end{array}$ & $\begin{array}{r}1,28 \mathrm{E}-02 \\
1,39 \mathrm{E}-02 \\
13,6 \\
\end{array}$ & $\begin{array}{r}1,52 \mathrm{E}-04 \\
1,88 \mathrm{E}-04 \\
11,9 \\
\end{array}$ & $\begin{array}{r}-1,34 \mathrm{E}-06 \\
2,04 \mathrm{E}-06 \\
-9,7 \\
\end{array}$ & $\begin{array}{r}6,90 \mathrm{E}-04 \\
1,32 \mathrm{E}-03 \\
7,7 \\
\end{array}$ & $\begin{array}{r}3,63 \mathrm{E}-06 \\
7,54 \mathrm{E}-06 \\
7,1\end{array}$ \\
\hline Big & $\begin{array}{l}\text { Ave } \\
\text { Std } \\
\text { t-stat }\end{array}$ & $\begin{array}{r}-5,06 \mathrm{E}-02 \\
1,47 \mathrm{E}-02 \\
-51,0\end{array}$ & $\begin{array}{r}1,64 \mathrm{E}-02 \\
4,37 \mathrm{E}-02 \\
5,6\end{array}$ & $\begin{array}{r}1,16 \mathrm{E}-02 \\
4,31 \mathrm{E}-02 \\
4,0\end{array}$ & $\begin{array}{r}1,07 \mathrm{E}-04 \\
5,35 \mathrm{E}-04 \\
3,0\end{array}$ & $\begin{array}{r}4,90 \mathrm{E}-06 \\
2,83 \mathrm{E}-05 \\
2,6\end{array}$ & $\begin{array}{r}9,03 \mathrm{E}-05 \\
8,14 \mathrm{E}-04 \\
1,6\end{array}$ & $\begin{array}{r}-4,93 \mathrm{E}-06 \\
4,31 \mathrm{E}-05 \\
-1,7\end{array}$ \\
\hline Small & $\begin{array}{l}\text { Ave } \\
\text { Std } \\
\text { t-stat }\end{array}$ & $\begin{array}{r}-9,52 \mathrm{E}-02 \\
2,31 \mathrm{E}-02 \\
-60,9\end{array}$ & $\begin{array}{r}-8,21 \mathrm{E}-03 \\
8,54 \mathrm{E}-03 \\
-14,2\end{array}$ & $\begin{array}{r}1,17 \mathrm{E}-02 \\
3,82 \mathrm{E}-02 \\
4,5\end{array}$ & $\begin{array}{r}2,27 \mathrm{E}-04 \\
2,84 \mathrm{E}-04 \\
11,8\end{array}$ & $\begin{array}{r}2,58 \mathrm{E}-07 \\
1,36 \mathrm{E}-05 \\
0,3\end{array}$ & $\begin{array}{r}1,46 \mathrm{E}-03 \\
2,26 \mathrm{E}-03 \\
9,5\end{array}$ & $\begin{array}{r}1,33 \mathrm{E}-05 \\
9,15 \mathrm{E}-05 \\
2,2\end{array}$ \\
\hline Micro & $\begin{array}{l}\text { Ave } \\
\text { Std } \\
\text { t-stat }\end{array}$ & $\begin{array}{r}-3,90 \mathrm{E}-02 \\
1,14 \mathrm{E}-02 \\
-50,5 \\
\end{array}$ & $\begin{array}{r}8,47 \mathrm{E}-04 \\
2,14 \mathrm{E}-03 \\
5,9 \\
\end{array}$ & $\begin{array}{r}1,49 \mathrm{E}-02 \\
3,38 \mathrm{E}-02 \\
6,5 \\
\end{array}$ & $\begin{array}{r}2,09 \mathrm{E}-04 \\
2,21 \mathrm{E}-04 \\
14,0 \\
\end{array}$ & $\begin{array}{r}-2,15 \mathrm{E}-06 \\
6,67 \mathrm{E}-06 \\
-4,8 \\
\end{array}$ & $\begin{array}{r}5,11 \mathrm{E}-04 \\
1,32 \mathrm{E}-03 \\
5,7 \\
\end{array}$ & $\begin{array}{r}4,43 \mathrm{E}-06 \\
1,06 \mathrm{E}-05 \\
6,2 \\
\end{array}$ \\
\hline
\end{tabular}

(b) Five parameter regression model

\begin{tabular}{|c|c|c|c|c|c|c|}
\hline Size Group & Stat Par & NS & Mom & Accr & dA/A & $\begin{array}{l}\text { Y/B } \\
\end{array}$ \\
\hline All & $\begin{array}{l}\text { Ave } \\
\text { Std }\end{array}$ & $\begin{array}{l}5,09 \mathrm{E}-03 \\
1,40 \mathrm{E}-02\end{array}$ & $\begin{array}{l}1,51 \mathrm{E}-04 \\
1,87 \mathrm{E}-04\end{array}$ & $\begin{array}{r}-1,22 \mathrm{E}-06 \\
1,98 \mathrm{E}-06\end{array}$ & $\begin{array}{l}4,38 \mathrm{E}-04 \\
1,35 \mathrm{E}-03\end{array}$ & $\begin{array}{r}4,21 \mathrm{E}-06 \\
8,79 \mathrm{E}-06 \\
71\end{array}$ \\
\hline Big & Ave & $4.30 \mathrm{E}-04$ & $2,68 \mathrm{E}-04$ & $3,33 \mathrm{E}-06$ & 1.19E-04 & $-2,61 \mathrm{E}-06$ \\
\hline & Std & 4,64E-02 & 5,79E-04 & 2,84E-05 & 9,93E-04 & 4,24E-05 \\
\hline & t-stat & 0,1 & 6,8 & 1,7 & 1,8 & $-0,9$ \\
\hline Small & $\begin{array}{l}\text { Ave } \\
\text { Std }\end{array}$ & $\begin{array}{r}-7,41 \mathrm{E}-04 \\
4,07 \mathrm{E}-02\end{array}$ & $\begin{array}{l}4,05 \mathrm{E}-04 \\
3,21 \mathrm{E}-04\end{array}$ & $\begin{array}{l}2,33 \mathrm{E}-06 \\
1,63 \mathrm{E}-05\end{array}$ & $\begin{array}{l}1,84 \mathrm{E}-04 \\
1,80 \mathrm{E}-03\end{array}$ & $\begin{array}{r}-1,38 \mathrm{E}-06 \\
1,47 \mathrm{E}-04\end{array}$ \\
\hline & t-stat & $-0,3$ & 18,6 & 2,1 & 1,5 & $-0,1$ \\
\hline Micro & $\begin{array}{l}\text { Ave } \\
\text { Std } \\
\text { t-stat }\end{array}$ & $\begin{array}{r}-6,40 \mathrm{E}-03 \\
3,59 \mathrm{E}-02 \\
-2,6\end{array}$ & $\begin{array}{r}1,83 \mathrm{E}-04 \\
2,10 \mathrm{E}-04 \\
12,8\end{array}$ & $\begin{array}{r}-1,97 \mathrm{E}-06 \\
6,90 \mathrm{E}-06 \\
-4,2\end{array}$ & $\begin{array}{r}1,40 \mathrm{E}-04 \\
1,09 \mathrm{E}-03 \\
1,9\end{array}$ & $\begin{array}{r}4,64 \mathrm{E}-06 \\
1,56 \mathrm{E}-05 \\
4,4\end{array}$ \\
\hline
\end{tabular}

Table 4: Average regression residual values per sorted category, with sorts performed with respect to each regression input variable

\begin{tabular}{|c|c|c|c|c|c|c|}
\hline Parameters & Categories & 1 & 2 & 3 & 4 & 5 \\
\hline Pred Ret & $\begin{array}{l}\text { Ave } \\
\text { Std } \\
\text { t Stat } \\
\text { Ave }\end{array}$ & $\begin{array}{r}-0,006 \\
0,125 \\
-3,025 \\
-0,128\end{array}$ & $\begin{array}{r}-0,012 \\
0,108 \\
-5,955 \\
-0,027\end{array}$ & $\begin{array}{r}-0,014 \\
0,124 \\
-6,846 \\
0,023\end{array}$ & \begin{tabular}{r}
\multicolumn{1}{c}{+015} \\
0,132 \\
$-7,151$ \\
0,043
\end{tabular} & $\begin{array}{r}0,023 \\
0,181 \\
11,312 \\
0,064\end{array}$ \\
\hline MC & $\begin{array}{l}\text { Std } \\
\text { t Stat } \\
\text { Ave }\end{array}$ & $\begin{array}{r}0,104 \\
-61,578 \\
-0,306\end{array}$ & $\begin{array}{r}0,138 \\
-12,865 \\
-0,146\end{array}$ & $\begin{array}{r}0,129 \\
10,910 \\
-0,035\end{array}$ & $\begin{array}{r}0,109 \\
20,588 \\
0,084\end{array}$ & $\begin{array}{r}0,095 \\
30,857 \\
0,371\end{array}$ \\
\hline Momentum & $\begin{array}{l}\text { Std } \\
\text { t Stat } \\
\text { Ave }\end{array}$ & $\begin{array}{r}0,079 \\
-147,702 \\
-0,027 \\
\end{array}$ & $\begin{array}{r}0,095 \\
-70,470 \\
0,066 \\
\end{array}$ & $\begin{array}{r}0,109 \\
-17,028 \\
0,041 \\
\end{array}$ & $\begin{array}{r}0,127 \\
40,568 \\
-0,010 \\
\end{array}$ & $\begin{array}{r}0,150 \\
179,153 \\
-0,092 \\
\end{array}$ \\
\hline $\mathrm{B} / \mathrm{M}$ & $\begin{array}{l}\text { Std } \\
\text { t Stat } \\
\text { Ave }\end{array}$ & $\begin{array}{r}0,096 \\
-13,187 \\
-0,009\end{array}$ & $\begin{array}{r}0,111 \\
31,984 \\
-0,041\end{array}$ & $\begin{array}{r}0,123 \\
19,556 \\
-0,033\end{array}$ & $\begin{array}{r}0,135 \\
-4,614 \\
0,016\end{array}$ & $\begin{array}{r}0,122 \\
-44,191 \\
0.041\end{array}$ \\
\hline NS & $\begin{array}{l}\text { Std } \\
\text { t Stat } \\
\text { Ave }\end{array}$ & $\begin{array}{r}0,116 \\
-4,307 \\
-0,031 \\
\end{array}$ & $\begin{array}{r}0,109 \\
-19,627 \\
-0,028 \\
\end{array}$ & $\begin{array}{r}0,103 \\
-15,872 \\
-0,010 \\
\end{array}$ & $\begin{array}{l}0,117 \\
7,886 \\
0,019\end{array}$ & $\begin{array}{r}0,120 \\
20,023 \\
0,026 \\
\end{array}$ \\
\hline Accr & $\begin{array}{l}\text { Std } \\
\text { t Stat } \\
\text { Ave }\end{array}$ & $\begin{array}{r}0,112 \\
-14,977 \\
0,014\end{array}$ & $\begin{array}{r}0,109 \\
-13,664 \\
-0,010\end{array}$ & $\begin{array}{r}0,104 \\
-4,861 \\
-0,009\end{array}$ & $\begin{array}{r}0,122 \\
9,397 \\
-0,015\end{array}$ & $\begin{array}{r}0,125 \\
12,384 \\
-0,004\end{array}$ \\
\hline deltaAssets & $\begin{array}{l}\text { Std } \\
\text { t Stat } \\
\text { Ave }\end{array}$ & $\begin{array}{r}0,112 \\
6,910 \\
-0,065 \\
\end{array}$ & $\begin{array}{r}0,115 \\
-4,962 \\
-0,029\end{array}$ & $\begin{array}{r}0,111 \\
-4,221 \\
0,013\end{array}$ & $\begin{array}{r}0,106 \\
-7,350 \\
0,036\end{array}$ & $\begin{array}{r}0,109 \\
-1,756 \\
0,021\end{array}$ \\
\hline $\mathrm{Y} / \mathrm{B}$ & $\begin{array}{l}\text { Std } \\
\text { t Stat }\end{array}$ & $\begin{array}{r}0,106 \\
-31,187\end{array}$ & $\begin{array}{r}0,106 \\
-14,201\end{array}$ & $\begin{array}{l}0,127 \\
6,301\end{array}$ & $\begin{array}{r}0,125 \\
17,288\end{array}$ & $\begin{array}{r}0,111 \\
10,154\end{array}$ \\
\hline
\end{tabular}

The first results that are displayed are residuals sorted based on the predicted return values, using the regression model for predicting future returns. It can be seen that for low predicted values the actual returns were substantially lower than the linear regression predicted values (t-statistic of $-3,0)$, while at the high end of the range actual returns were significantly higher than the linear prediction (t-statistic of 11,3 ). This provides a clear indication that the linear model does not fully describe the impact of the indicator variables on future returns, and that a nonlinear model may potentially capture these relationships more accurately.

When the same phenomenon is studied for the individual indicators the observations are similar; e.g. in the case of MC (that is negatively correlated with future returns) the residuals are negative at the low end of the MC range (where returns tend to be high) and positive at the high end of the range (where 
returns tend to be low), indicating that the actual relation between $\mathrm{MC}$ and returns tend to bend upwards and downwards respectively from a linear relationship at the two ends of the $\mathrm{MC}$ range. In the case of $\mathrm{B} / \mathrm{M}$ and Momentum, that are positively correlated with future returns, a similar effect is observed, once again with a statistically significant trend of residual values across the respective sorted categories. Overall it would appear that it may be a worthwhile exercise to experiment with a model that allows for a moderate degree of nonlinearity in the relationships between explanatory variables and future returns. To the best of our knowledge no previous results indicative of inherently nonlinear relationships between explanatory variables and future returns have been reported for JSE stocks.

The above results for regression residuals can be viewed as an extension of the earlier results of Basiewicz and Auret (2010), who demonstrated that a three factor model including the size effect, value effect and a market factor could be used to model cross-sectional return differentials. Basiewicz and Auret also found that some size effects remained after extracting the three-factor model, which is indicative of a possible non-linear relationship between returns and the explanatory variables.

\subsection{Evaluating predictors based on sorted returns}

The results reported in this section more or less follows the same formats as used by FF, with the addition of data on risk measures applied to the returns data as explained below.

Table 5 displays the values of sorted returns for the above set of explanatory variables, as well as the tstatistics for sorted returns. Both equally weighted and value weighted returns were calculated as described in the section on Research Methodology. To allow the evaluation of sorted category returns on a riskcompensated basis we include the Sharpe and Treynor risk measures in each case.

In addition to the sorted category returns the value and $\mathrm{t}$-statistic of the hedge portfolio returns (difference between the returns of the highest and lowest sorted return categories) are also calculated for each sorting parameter, as displayed in Table 6. Should the explanatory variable be positively (negatively) correlated with future returns a long position will be taken for stocks in category 5 (category 1 ) and a short position taken for stocks in category 1 (category 5). The hedge portfolio returns can be viewed as a summary measure of the potential value of the explanatory variable for the compilation of portfolios that will outperform the market.

Table 5: Sorted returns and t-statistics as well as risk-adjusted performance measures for the set of explanatory variables

\begin{tabular}{|c|c|c|c|c|c|c|c|c|c|c|c|}
\hline \multirow{2}{*}{ Parameters } & \multirow{2}{*}{ Categories } & \multicolumn{5}{|c|}{ EqW } & \multicolumn{5}{|c|}{ ValW } \\
\hline & & 1 & 2 & 3 & 4 & 5 & 1 & 2 & 3 & 4 & 5 \\
\hline \multirow[t]{5}{*}{ MC } & Ave & 0,053 & 0,011 & 0,009 & 0,005 & 0,007 & 0,029 & 0,010 & 0,009 & 0,005 & 0,006 \\
\hline & Std & 0,116 & 0,055 & 0,062 & 0,051 & 0,055 & 0,074 & 0,062 & 0,057 & 0,052 & 0,063 \\
\hline & t Stat & 17,315 & $-2,675$ & $-3,852$ & $-5,935$ & $-4,601$ & 29,360 & 4,972 & 3,378 & $-0,827$ & 0,194 \\
\hline & Sharpe PM & 0,394 & 0,082 & 0,033 & $-0,044$ & 0,009 & 0,297 & 0,048 & 0,031 & $-0,030$ & $-0,012$ \\
\hline & Treynor PM & 0,029 & 0,005 & 0,002 & $-0,003$ & 0,001 & 0,063 & 0,005 & 0,003 & $-0,002$ & $-0,001$ \\
\hline \multirow[t]{5}{*}{ Momentum } & Ave & 0,032 & 0,007 & 0,008 & 0,011 & 0,026 & $-0,010$ & $-0,002$ & 0,008 & 0,008 & 0,015 \\
\hline & Std & 0,115 & 0,057 & 0,049 & 0,045 & 0,065 & 0,094 & 0,077 & 0,062 & 0,064 & 0,081 \\
\hline & t Stat & 7,389 & $-4,584$ & $-4,218$ & $-2,854$ & 4,313 & $-20,400$ & $-10,480$ & 2,194 & 3,042 & 12,216 \\
\hline & Sharpe PM & 0,220 & 0,010 & 0,027 & 0,091 & 0,294 & $-0,179$ & $-0,117$ & 0,013 & 0,023 & 0,107 \\
\hline & Treynor PM & 0,015 & 0,001 & 0,002 & 0,006 & 0,019 & $-0,018$ & $-0,010$ & 0,001 & 0,002 & 0,008 \\
\hline \multirow[t]{5}{*}{$\mathrm{B} / \mathrm{M}$} & Ave & 0,016 & 0,011 & 0,010 & 0,014 & 0,034 & 0,000 & 0,003 & 0,011 & 0,014 & 0,022 \\
\hline & Std & 0,097 & 0,066 & 0,051 & 0,056 & 0,063 & 0,077 & 0,071 & 0,060 & 0,057 & 0,070 \\
\hline & t Stat & $-0,336$ & $-2,874$ & $-3,494$ & $-1,546$ & 8,208 & $-7,323$ & $-3,767$ & 6,669 & 9,865 & 20,489 \\
\hline & Sharpe PM & 0,096 & 0,062 & 0,055 & 0,122 & 0,432 & $-0,085$ & $-0,054$ & 0,072 & 0,119 & 0,215 \\
\hline & Treynor PM & 0,007 & 0,004 & 0,003 & 0,008 & 0,028 & $-0,006$ & $-0,004$ & 0,005 & 0,009 & 0,021 \\
\hline \multirow[t]{5}{*}{ NS } & Ave & 0,022 & 0,016 & 0,014 & 0,015 & 0,018 & 0,009 & 0,001 & 0,008 & 0,007 & 0,003 \\
\hline & Std & 0,090 & 0,066 & 0,056 & 0,062 & 0,065 & 0,070 & 0,070 & 0,061 & 0,068 & 0,069 \\
\hline & t Stat & 2,646 & $-0,550$ & $-1,593$ & $-0,910$ & 0,534 & 3,548 & $-6,809$ & 2,512 & 1,042 & $-4,258$ \\
\hline & Sharpe PM & 0,172 & 0,136 & 0,121 & 0,132 & 0,171 & 0,027 & $-0,089$ & 0,017 & $-0,001$ & $-0,061$ \\
\hline & Treynor PM & 0,012 & 0,009 & 0,008 & 0,009 & 0,011 & 0,002 & $-0,007$ & 0,001 & 0,000 & $-0,004$ \\
\hline \multirow[t]{5}{*}{$\mathrm{Y} / \mathrm{B}$} & Ave & 0,018 & 0,014 & 0,018 & 0,014 & 0,020 & $-0,001$ & 0,005 & 0,007 & 0,008 & 0,007 \\
\hline & Std & 0,066 & 0,060 & 0,063 & 0,053 & 0,093 & 0,083 & 0,060 & 0,070 & 0,061 & 0,074 \\
\hline & t Stat & 0,459 & $-1,400$ & 0,544 & $-1,205$ & 1,726 & $-8,531$ & $-1,476$ & 1,821 & 2,489 & 1,018 \\
\hline & Sharpe PM & 0,167 & 0,118 & 0,178 & 0,142 & 0,147 & $-0,091$ & $-0,034$ & 0,007 & 0,017 & $-0,001$ \\
\hline & Treynor PM & 0,011 & 0,009 & 0,011 & 0,009 & 0,010 & $-0,007$ & $-0,003$ & 0,001 & 0,001 & 0,000 \\
\hline \multirow[t]{5}{*}{ Accr } & Ave & 0,020 & 0,013 & 0,013 & 0,018 & 0,021 & 0,005 & 0,005 & 0,008 & 0,008 & 0,007 \\
\hline & Std & 0,064 & 0,073 & 0,059 & 0,060 & 0,079 & 0,067 & 0,074 & 0,058 & 0,063 & 0,080 \\
\hline & t Stat & 1,536 & $-1,869$ & $-1,991$ & 0,455 & 1,955 & $-1,685$ & $-0,700$ & 2,489 & 2,833 & 1,180 \\
\hline & Sharpe PM & 0,206 & 0,085 & 0,101 & 0,183 & 0,178 & $-0,033$ & $-0,020$ & 0,018 & 0,021 & 0,000 \\
\hline & Treynor PM & 0,013 & 0,006 & 0,008 & 0,011 & 0,012 & $-0,002$ & $-0,001$ & 0,001 & 0,001 & 0,000 \\
\hline \multirow[t]{5}{*}{ dA/A } & Ave & 0,021 & 0,018 & 0,016 & 0,014 & 0,015 & 0,010 & 0,000 & 0,001 & 0,007 & 0,009 \\
\hline & Std & 0,079 & 0,077 & 0,066 & 0,059 & 0,054 & 0,074 & 0,079 & 0,062 & 0,072 & 0,058 \\
\hline & t Stat & 1,841 & 0,590 & $-0,235$ & $-1,354$ & $-0,716$ & 5,694 & $-8,010$ & $-5,720$ & 0,947 & 4,233 \\
\hline & Sharpe PM & 0,175 & 0,146 & 0,145 & 0,122 & 0,158 & 0,048 & $-0,090$ & $-0,086$ & $-0,002$ & 0,041 \\
\hline & Treynor PM & 0,012 & 0,010 & 0,010 & 0,008 & 0,010 & 0,003 & $-0,007$ & $-0,007$ & 0,000 & 0,003 \\
\hline
\end{tabular}


Table 6: Hedge portfolio returns and t-statistics for the set of explanatory variables and for the different size categories All, Micro, Small and Big

\begin{tabular}{|c|c|c|c|c|c|c|c|c|c|}
\hline \multicolumn{2}{|c|}{ Parameter } & \multicolumn{2}{|c|}{ All } & \multicolumn{2}{|c|}{ Micro } & \multicolumn{2}{|c|}{ Small } & \multicolumn{2}{|c|}{ Big } \\
\hline & & Eq W & Val W & Eq W & Val W & Eq W & Val W & Eq W & Val W \\
\hline \multirow[t]{2}{*}{ MC } & High - Low & $-0,045$ & $-0,023$ & $-0,066$ & $-0,039$ & 0,005 & 0,005 & $-0,001$ & $-0,003$ \\
\hline & $\mathrm{H}-\mathrm{L}$ t Stat & $-21,915$ & $-29,166$ & $-24,428$ & $-14,535$ & 2,834 & 2,697 & $-0,435$ & $-1,404$ \\
\hline \multirow{2}{*}{$\begin{array}{l}\text { Momen- } \\
\text { tum }\end{array}$} & High - Low & $-0,006$ & 0,025 & $-0,010$ & 0,014 & 0,019 & 0,018 & 0,020 & 0,024 \\
\hline & H - L t Stat & $-3,075$ & 32,616 & $-3,671$ & 5,216 & 10,007 & 9,288 & 10,980 & 13,316 \\
\hline \multirow[t]{2}{*}{$\mathrm{B} / \mathrm{M}$} & High - Low & 0,018 & 0,022 & 0,012 & 0,022 & 0,020 & 0,019 & 0,015 & 0,013 \\
\hline & $\mathrm{H}-\mathrm{L}$ t Stat & 8,544 & 27,812 & 4,513 & 8,071 & 10,681 & 9,755 & 8,204 & 7,303 \\
\hline \multirow[t]{2}{*}{ NS } & High - Low & $-0,004$ & $-0,006$ & $-0,037$ & $-0,011$ & 0,004 & 0,002 & 0,010 & 0,003 \\
\hline & $\mathrm{H}$ - L t Stat & $-2,111$ & $-7,806$ & $-13,755$ & $-3,904$ & 1,893 & 1,042 & 5,458 & 1,543 \\
\hline \multirow[t]{2}{*}{ Y/B } & High - Low & 0,003 & 0,007 & $-0,003$ & $-0,003$ & 0,017 & 0,018 & 0,005 & 0,004 \\
\hline & $\mathrm{H}-\mathrm{L}$ t Stat & 1,267 & 9,549 & $-0,958$ & $-1,113$ & 8,765 & 9,202 & 2,703 & 2,288 \\
\hline \multirow[t]{2}{*}{ Accr } & High - Low & 0,001 & 0,002 & $-0,001$ & 0,004 & 0,005 & 0,003 & 0,000 & $-0,001$ \\
\hline & $\mathrm{H}-\mathrm{L}$ t Stat & 0,419 & 2,866 & $-0,481$ & 1,371 & 2,813 & 1,640 & $-0,090$ & $-0,596$ \\
\hline \multirow[t]{2}{*}{ dA/A } & High - Low & $-0,005$ & $-0,001$ & $-0,066$ & $-0,029$ & 0,006 & 0,004 & $-0,001$ & $-0,007$ \\
\hline & H - L t Stat & $-2,558$ & $-1,461$ & $-24,360$ & $-10,628$ & 2,952 & 2,120 & $-0,575$ & $-3,859$ \\
\hline
\end{tabular}

To allow a comparison between sorted returns for the four stock categories (All, Big, Small and Micro) we also include Table 7 that displays for each stock category the t-statistics of average sorted returns per explanatory variable. Once again the results are repeated using both equally weighted and value weighted returns.

As could be expected MC displays the most prominent extreme returns and corresponding t-statistics of all indicators. For the All stocks category the decrease in future returns with increase in $\mathrm{MC}$ is almost consistent across all sorted categories in the case of both equally weighted returns and value weighted returns. Tstatistics are specifically prominent in the lowest MC category (t-statistics of 17,3 and 29,4 respectively for EqW and ValW returns), but also significant in the highest MC category for EqW returns (t-statistics of $4,6)$. For ValW returns the values are somewhat different but still almost consistently decreasing across the sorted categories. It is clear that the lower sorted categories dominated by Micro stocks display by far the most extreme return behaviour. The negative relationship between $M C$ and returns is however reversed for the last sorted category, where a small increase in returns is observed.

The substantial differences in t-statistics that are observed for the EqW and ValW measures of return can be explained as follows: as Micro stocks are the most numerous of all stock categories, they tend to skew the average return results towards the high side in the case of EqW returns, while, based on their large market cap, Big stocks dominate the average return value calculation in the case of ValW returns. At the same time the standard deviation of returns for the total population (which is used in the calculation of the t-statistics) tend to be higher in the case of EqW returns (due to the volatility of Micro stocks), whereas standard deviation comes out somewhat lower when using ValW returns (based on the relative stability of Big stock returns). This result in a lower absolute return value but higher t-statistic for the lowest MC category in the case of ValW returns compared to EqW returns, while the opposite is true for the highest MC category.

When studying the impact of $\mathrm{MC}$ within the respective size categories Micro, Small and Big, there is a strong relationship across most MC categories for Micro stocks as displayed in Table 7. This relationship is however much weaker amongst the Small and Big stocks, where future returns do not consistently decrease across the size groups. The reversed relationship between $\mathrm{MC}$ and returns for the highest sorted categories in the case of All stocks can be studied more closely by observing the behaviour of MC for the sorted categories of Big stocks. It can be seen that there is no clear trend, either increasing or decreasing, across the Big MC sorted categories. The same lack of a strong relationship between MC and returns is also apparent for Small stocks. The relationship between $\mathrm{MC}$ and returns therefore seems to be largely restricted to Micro stocks. This important phenomenon is revealed neither by the correlation or regression analyses, nor by any of the earlier JSE studies on the size effect. 
Table 7: Sorted returns t-statistics for the set of explanatory variables and for different size groups

\begin{tabular}{|c|c|c|c|c|c|c|c|c|c|c|c|}
\hline \multirow{2}{*}{ Parameters } & \multirow{2}{*}{ Categories } & \multicolumn{5}{|c|}{ EqW Ret } & \multicolumn{5}{|c|}{ ValW Ret } \\
\hline & & 1 & 2 & 3 & 4 & 5 & 1 & 2 & 3 & 4 & 5 \\
\hline \multirow[t]{4}{*}{ MC } & All & 17,31 & $-2,68$ & $-3,85$ & $-5,94$ & $-4,60$ & 29,36 & 4,97 & 3,38 & $-0,83$ & 0,19 \\
\hline & Big & 1,34 & $-0,79$ & $-1,63$ & $-0,39$ & 0,90 & 1,63 & $-0,26$ & $-0,86$ & $-0,21$ & 0,23 \\
\hline & Small & $-1,13$ & $-0,35$ & 0,36 & $-1,46$ & 1,70 & $-1,34$ & $-0,48$ & 0,12 & $-1,80$ & 1,36 \\
\hline & Micro & 17,87 & $-1,73$ & $-4,36$ & $-5,05$ & $-6,56$ & 13,72 & 3,52 & 0,90 & 0,60 & $-0,81$ \\
\hline \multirow{4}{*}{$\begin{array}{l}\text { Momen- } \\
\text { tum }\end{array}$} & All & 7,39 & $-4,58$ & $-4,22$ & $-2,85$ & 4,31 & $-20,40$ & $-10,48$ & 2,19 & 3,04 & 12,22 \\
\hline & Big & $-5,94$ & $-0,44$ & 0,20 & $-0,18$ & 5,04 & $-8,31$ & 0,04 & 2,05 & 0,40 & 5,00 \\
\hline & Small & $-4,86$ & $-0,86$ & $-1,10$ & 0,60 & 5,15 & $-3,99$ & $-0,73$ & $-1,35$ & $-0,54$ & 5,30 \\
\hline & Micro & 6,48 & $-2,14$ & $-4,23$ & $-3,06$ & 2,81 & $-0,71$ & $-4,06$ & $-1,54$ & 0,62 & 4,50 \\
\hline \multirow[t]{4}{*}{$\mathrm{B} / \mathrm{M}$} & All & $-0,34$ & $-2,87$ & $-3,49$ & $-1,55$ & 8,21 & $-7,32$ & $-3,77$ & 6,67 & 9,87 & 20,49 \\
\hline & Big & $-4,78$ & $-1,70$ & $-0,20$ & 2,33 & 3,43 & $-2,18$ & $-3,67$ & 1,13 & 3,35 & 5,13 \\
\hline & Small & $-6,53$ & 0,27 & 0,73 & 0,33 & 4,15 & $-6,05$ & 0,06 & 0,39 & 0,86 & 3,70 \\
\hline & Micro & 3,14 & $-4,89$ & $-3,52$ & $-2,70$ & 7,65 & $-1,07$ & $-1,74$ & $-0,01$ & 0,48 & 7,00 \\
\hline \multirow[t]{4}{*}{ NS } & All & 2,65 & $-0,55$ & $-1,59$ & $-0,91$ & 0,53 & 3,55 & $-6,81$ & 2,51 & 1,04 & $-4,26$ \\
\hline & Big & $-3,93$ & 0,05 & 2,16 & $-0,56$ & 1,52 & $-2,23$ & 0,71 & 3,50 & $-1,87$ & $-0,68$ \\
\hline & Small & $-1,97$ & $-1,99$ & 1,32 & 1,93 & $-0,08$ & $-1,37$ & $-2,55$ & 0,65 & 1,88 & $-0,33$ \\
\hline & Micro & 13,77 & $-4,62$ & $-6,17$ & $-3,01$ & 0,01 & 3,14 & 1,05 & $-0,61$ & 0,50 & $-0,76$ \\
\hline \multirow[t]{4}{*}{$\mathrm{Y} / \mathrm{B}$} & All & 0,46 & $-1,40$ & 0,54 & $-1,21$ & 1,73 & $-8,53$ & $-1,48$ & 1,82 & 2,49 & 1,02 \\
\hline & Big & $-3,93$ & 2,38 & 2,09 & 0,39 & $-1,22$ & $-2,38$ & 1,27 & 1,29 & 1,50 & $-0,09$ \\
\hline & Small & $-5,53$ & $-0,91$ & 1,68 & 0,57 & 3,23 & $-5,69$ & $-0,86$ & 1,23 & 0,15 & 3,52 \\
\hline & Micro & 3,79 & $-4,88$ & 0,15 & $-1,97$ & 2,83 & 0,74 & $-2,11$ & 0,91 & 0,87 & $-0,37$ \\
\hline \multirow[t]{4}{*}{ Accr } & All & 1,54 & $-1,87$ & $-1,99$ & 0,46 & 1,95 & $-1,69$ & $-0,70$ & 2,49 & 2,83 & 1,18 \\
\hline & Big & $-0,92$ & $-1,65$ & 2,56 & 0,80 & $-1,01$ & 0,20 & 1,36 & 0,33 & $-0,22$ & $-0,39$ \\
\hline & Small & $-0,91$ & $-3,78$ & $-1,14$ & 3,18 & 1,91 & $-0,45$ & $-2,17$ & $-1,88$ & 3,20 & 1,19 \\
\hline & Micro & 1,96 & 1,84 & $-6,27$ & 1,00 & 1,48 & $-1,10$ & 1,67 & $-2,51$ & 1,85 & 0,27 \\
\hline \multirow[t]{4}{*}{ dA/A } & All & 1,84 & 0,59 & $-0,23$ & $-1,35$ & $-0,72$ & 5,69 & $-8,01$ & $-5,72$ & 0,95 & 4,23 \\
\hline & Big & 2,48 & $-0,96$ & $-2,51$ & $-1,51$ & 1,90 & 4,15 & $-0,54$ & $-1,33$ & $-0,80$ & 0,29 \\
\hline & Small & $-0,89$ & $-1,47$ & $-0,25$ & $-0,40$ & 2,07 & $-0,81$ & $-1,64$ & $-0,53$ & $-0,72$ & 1,31 \\
\hline & Micro & 18,02 & $-2,05$ & $-4,42$ & $-5,04$ & $-6,34$ & 9,81 & 3,39 & 0,86 & 0,58 & $-0,82$ \\
\hline
\end{tabular}

To further demonstrate the usefulness of the sorted returns approach: in Table 7 it can be seen that for Small stocks the highest average returns are not earned by stocks falling the in the $1^{\text {st }}$ sorted MC category, as might have been assumed from the results of the correlation and regression analyses. It is therefore demonstrated that the sorted returns approach does not only measure the aggregate effect across all stocks, but also captures the more detailed behaviour of the relationship across specific stock categories. This can be of significant value to a portfolio manager when selecting stocks within specific size categories aimed at maximizing returns.

It is therefore clear that the size effect is dominated by Micro stocks, with only a weak size effect remaining if these stocks are excluded. This is an important observation regarding the practical value of $M C$ as stock selection criterion, given that Micro stocks are of limited use for investors that manage substantial investment funds, due to the lack of trading volumes and small number of available shares for Micro stocks. For those investors that are in a position to exploit the high returns offered by Micro stocks it would be of interest to know to what extent these high returns are a result of high risk due to the volatile nature of Micro stocks. For this purpose we use the Sharpe and Treynor performance measures to obtain the riskadjusted returns for each sorted category. It is clear from the values in Table 5 that for both of these measures there is a more or less consistent increase in risk-adjusted returns from higher to lower MC categories, both for EqW and for ValW returns, confirming that even after adjusting for risk $\mathrm{MC}$ can be a useful indicator for abnormal returns. This effect is however much weaker in the Small and Big size categories (results not shown here). As the effect of $M C$ is mostly confined to the Micro category its value for the larger investor is therefore limited, while small investors will have to deal with the negative impact of high trading costs applicable to small trades as well as potentially large bid-ask spreads and thin trading volumes. Further work is hence required before any confident statement can be made regarding the practical usefulness of $\mathrm{MC}$ for stock selection.

Amongst the remaining indicators $B / M$ displays a positive relationship with future returns and high tstatistic in the extreme sorted categories, more prominently so for ValW returns compared to EqW returns, as well as positive hedge portfolio return, which is in line with the results of FF and others as 
observed on the NYSE, as well as with previous research for stocks listed on the JSE and with the results of the correlation and regression analyses. The most consistent relationship between $\mathrm{B} / \mathrm{M}$ and future returns is observed using the ValW measure for returns. When including all shares the extreme tstatistics of the sorted category returns range from $-7,3$ for the lowest B/M category to 20,5 for the highest category. A strong relationship is also observed for the Big and Small size categories, where the extreme tstatistics range from $-2,2$ to 5,1 and from $-6,1$ to 3,7 respectively. In the case of Micro stocks the range is $-1,1$ to 7,0 but with less consistency in the relationship across the sorted categories.

The positive relationship between $\mathrm{B} / \mathrm{M}$ and future returns, using EqW as return measure, is however reversed for the lowest All and Micro categories. This may be explained as follows: $\mathrm{B} / \mathrm{M}$ is essentially an indicator that identifies value stocks. Many of the Micro stocks are however viewed as growth stocks for which market value far exceeds book value based on the expectation of abnormally high future growth rates. In the lowest B/M category this growth stock effect seems to dominate the value stock effect observed across other categories.

When adjusting for risk it can be seen that the positive impact of higher $\mathrm{B} / \mathrm{M}$ values is not in any way negated by volatility related risk factors, as both the Sharpe and Treynor risk-adjusted ValW return measures display a consistent increase in performance with increase in $\mathrm{B} / \mathrm{M}$ value for both All and Big stocks. These results, as well as the results with respect to $\mathrm{MC}$, are thus in conflict with the findings of Robins et al. (1999) who could not demonstrate significant abnormal returns related to the size or value effects after compensating for risk.

The positive impact of Momentum is observed strongly across all size groups, with extreme t-statistics of $-20,4$ to 12,2 for All stocks, $-8,3$ to 5,0 for Big stocks, $-4,0$ to 5,3 for Small stocks and $-0,7$ to 4,5 for Micro stocks when using the ValW return measure. This is consistent with the results of FF as well as with earlier results on the JSE. In the case of net returns (i.e. where the impact of $\mathrm{MC}$ and $\mathrm{B} / \mathrm{M}$ has been removed results not displayed here) the strength of the relationship is only slightly reduced, with t-statistics varying across the sorted categories from $-5,7$ to 11,6 for All stocks, $-0,5$ to 3,9 for Big stocks, $-4,7$ to 3,6 for Small stocks and $-4,5$ to 2,4 for Micro stocks, again using the ValW return measure.

The increase in t-statistic moving from sorted Momentum category 1 to 5 within each size category is almost consistent when using the ValW return measure. More exceptions however occur when using the EqW return measure and for the lowest category of Micro stocks, where an increase in returns is observed from the second lowest to the lowest category. As could be expected this behaviour is also present in the lower EqW categories for All stocks, due to the dominating effect of Micro stocks for EqW returns. This indicates that the Micro cap stocks with the most negative Momentum display positive future returns, which can be viewed as a mean-reverting effect. Given the fact that in this paper both Momentum and future returns are measured over 12 month periods, it can be deduced that for Micro stocks the trends in return tend to be sustained for shorter time periods compared to larger stocks, and that the mean-reverting effect that has been widely observed amongst stocks in general may have a shorter reversion period for Micro stocks.

Risk-adjusted returns for All stocks according to both the Sharpe and Treynor performance measures display a uniform increase across the sorted Momentum categories when using ValW returns and almost a uniform increase when using the EqW return measure (the only exception being the decrease when moving from category 1 to 2), confirming that Momentum related excess returns is not explained by risk alone.

As regards the other fundamental indicators also studied by FF the observations are mostly in line with the correlation and regression analyses of the previous sections; in cases where conflicting results are obtained the sorted returns often provide more insights into the reasons for differences:

- NS displays a weak negatively correlated relationship with returns; when including all size categories and using the ValW return measure the abnormal sorted returns are statistically significant in the extremes in terms of the respective $t$ statistics; the effect is however substantially weaker than for any of $\mathrm{MC}, \mathrm{B} / \mathrm{M}$ or Momentum. The extreme category t-statistics are slightly reduced for net returns $(2,9$ and $-3,1)$ compared to nominal returns $(3,5$ to $-4,3)$ but is still statistically significant.

When studying the NS behaviour within the size categories, it is interesting to note that, using EqW returns, the NS effect as measured in terms of extreme category t-statistics is by far the strongest in the Micro category, both in terms of nominal $(13,8$ to $-3,0)$ and net $(8,0$ and $-3,8)$ returns. For the other two size categories the impact of NS almost seems to be reversed when moving across the sorted categories. When observing the sorted category t-statistics for All stocks it can be seen that the relationship between NS and returns is not linear: category returns are positive on both extremes ( 1 and 5 ), with negative returns for categories 2 to 4 . This explains why such confusing results were obtained for the linear regression analysis, with conflicting results 
between the 7 factor and the 5 factor regression analyses.

- $\quad \mathrm{Y} / \mathrm{B}$ has a strong positive relationship with ValW returns for the size categories Small and All stocks; this is somewhat weaker for the Big size category. This behaviour was sustained when calculating the net returns after compensating for the effects of $M C$ and $B / M$. It would therefore seem that the profitability of stocks does play an important role in the way that non-Micro stocks are evaluated by the market. It is however noted that for All and Big stocks there is a dip in returns from category 4 to 5 . This may be attributed to the fact that prominent stocks displaying strong earnings results are over-rewarded and subsequently generates lower returns as the share price reverts to more realistic levels. It is also noticeable that for Micro stocks the relationship between $Y / B$ and returns seems to be reversed. This may be a result of the fact that Micro stocks, many of which have not been listed for a long time, are evaluated more based on future growth potential rather than on currently profitability.

- For Accr the results for different size categories are in conflict: Micro stocks (and All stocks using EqW returns) display a weak negative relationship, while Big and Small stocks (and All stocks using ValW returns) display a weak positive relationship with Accr. This is in line with both the correlation and with the regression analyses which are effectively equally weighted returns techniques: the correlation coefficients with respect to Accr were negative and both All and Micro stocks had negative regression coefficients, whilst Big and Small stocks displayed a positive regression coefficient. It would therefore seem that Micro stocks are penalised and Big and Small stocks rewarded for increasing operational assets.

- A similar situation exists in the case of $d A / A$. For All stocks, with the exception of category 1, a positive relationship is observed across the remaining size categories when ValW is used as return measure (which is dominated by Big stocks), but this is reversed when using the EqW return measure (which is dominated by Micro stocks). In line with this result the relationship is positive within the Big and Small categories and negative in the Micro category. This is also in line with the negative cross-sectional correlation coefficients with respect to $d A / A$ (which are equally weighted). It would therefore appear that Big and Small stocks are in general rewarded for growth in assets, but that this does not play the same role for in the case of Micro stocks, where the relationship in fact seems to be the opposite. This is also in line with the finding of Bhana (2008) that firms are rewarded for announcing large capital expenditure projects, as it will mostly be firms in the Big category that will make such announcements.

\section{SUMMARY AND CONCLUSIONS}

Based on the empirical results reported in the previous sections it can be stated that this study provided further conclusive evidence against the $\mathrm{EMH}$; as a result we can reject the null hypothesis that the set of explanatory variables included in this study cannot be used in the construction of portfolios that will on average generate abnormal returns. This is supported by the fact that several of the explanatory variables, including $\mathrm{MC}, \mathrm{B} / \mathrm{M}$, Momentum, and to a lesser extent Y/B and NS, produced hedge portfolio returns that are significantly different from zero after compensating for risk.

When comparing our results representing stock behaviour on the JSE with those of Fama and French (2008) as observed on the NYSE, it can be stated that behaviour on the JSE associated with the four most prominent explanatory variables as identified above is in general similar to what is observed on the NYSE. Some differences are however observed within specific size categories as discussed above.

Before arriving at any final conclusions regarding the suitability of the different techniques that were employed to study these relationships, we need to critically compare the results as produced by the three different approaches. This will be done by first considering those explanatory variables for which the results produced by all techniques corresponds, and then by investigating those variables for which the results seem to be in conflict.

In the case of the three most significant explanatory variables (MC, B/M and Momentum) the case is clearcut: all three techniques produce similar results with consistent relationships across all size groups; there are however distinct differences with respect to the level of statistical significance of these relationships between different size groups:

- There is a negative relationship between future returns and $M C$, which is the strongest in the Micro size category; even within the Micro category this phenomenon is the strongest for the lowest $M C$ category and for equally weighted returns, which is dominated by the large number of very small stocks. While the MC based hedge portfolio returns of more than $4 \%$ per month (based on the EqW return measure) appears to be very attractive, the restriction of this phenomenon to very small stocks casts doubts on the degree to which MC can be practically exploited to earn significant superior returns for any but small investment portfolios. It was furthermore observed 
that the size effect is not uniform within the nonMicro size categories.

- A positive relationship exists between future returns (based on the ValW return measure) and $\mathrm{B} / \mathrm{M}$, which is consistent not only across all size groups, but also across all B/M sorted categories, and which persists after compensating for risk, confirming earlier evidence regarding the superior returns earned by value stocks compared to growth stocks. The $\mathrm{B} / \mathrm{M}$ phenomenon is least significant for Micro stocks but very significant in the Small and Big size categories, making it a more useful relationship to exploit compared to $\mathrm{MC}$, as the positive relationship with future returns specifically exists for those stocks that can make up the bulk of large investment portfolios. A B/M based hedge portfolio returns approximately 2,2\% per month using ValW, and even when restricting the choice to Big stocks only it is still a healthy $1,5 \%$ per month.

- Momentum similarly has a positive relationship with future returns that is approximately equally significant across all size categories and across all Momentum sorted categories, with hedge portfolio returns ranging between 1,4 and $2,5 \%$ per month. The positive effect of Momentum also persists after compensating for the effects of $M C$ and $B / M$ and when compensating for risk, confirming earlier evidence of short term persistence in stock returns. The one exception is that for the lowest sorted category of Micro stocks the sign of the relationship was inverted, probably indicating that the mean reverting phenomenon for stock returns kicks in more quickly for smaller stocks.

For the remaining explanatory variables the case is not as clear-cut: results are either not uniform across all size groups, or in conflict between the different analysis techniques, or inconclusive in terms of statistical significance:

- In the case of NS a weak negative relationship with future returns was observed for the All and Micro size categories. Omitting $\mathrm{MC}$ and $\mathrm{B} / \mathrm{M}$ from the regression model caused the NS coefficient to become more negative, in correspondence with the results from the correlation analysis and sorted returns. The sorted returns results however showed that the relationship between NS and returns in the Big and Small categories is nonlinear. It can therefore not be conclusively stated that stocks are in general penalized for issuing more shares. This relationship also weakens when compensating for risk. It is furthermore clear that caution should be applied when drawing conclusions from the parameters extracted for multivariate regression return prediction models, as the presence of more dominant variables (e.g. $\mathrm{MC}$ and $\mathrm{B} / \mathrm{M}$ ), as well as the inherent nonlinearity of the modelled relationships, may produce misleading results.

- In the case of Accr and dA/A there appears to be weak relationships but with opposite signs for Big and Small versus Micro stocks: whilst Big and Small stocks are rewarded for building assets Micro stocks are penalised. Careful studying of the different sorted category returns for both of these explanatory variables however shows that there is lack of consistency and statistical significance in their relationships with future returns across different sorted categories. It must therefore be concluded that whatever relationship may exist is not consistent over time and most likely not sufficiently strong to be exploited.

- $\quad \mathrm{Y} / \mathrm{B}$, which provides an indication of the profitability of stocks, displays a weak positive relationship with future returns which remains after compensating for the effect of $M C$ and $B / M$; the phenomenon however largely disappears after compensating for risk. When excluding Micro stocks the $\mathrm{Y} / \mathrm{B}$ effect is however more consistent, persisting after compensating for $\mathrm{MC}$ and $\mathrm{B} / \mathrm{M}$ as well as for risk, with a hedge portfolio return of $1,7 \%$ for Small stocks but only $0,49 \%$ for Big stocks. It confirms that profitability does play a role in the evaluation of larger stocks, and that the effect is strong enough to be exploited in practical portfolios. The highest returns for Big stocks may however not appear in the highest $\mathrm{Y} / \mathrm{B}$ sorted categories; this may be due to the over-pricing by the market of stocks with consistently high profitability levels.

The discussion above demonstrates that both correlation and cross-section regression analysis can provide misleading results when used on their own, depending on the set of variables included in the regression model, and that this can be partly attributed to correlations amongst the explanatory variables. Calculating the returns for sorted categories provides more detailed insights both regarding the nature as well as the statistical significance of the relationships between explanatory variables and future stock returns: it reveals what happens within each sorted category, whilst both correlation and regression analysis only display the aggregate effect of the respective relationships.

With respect to differences in behaviour between the different size categories it can be stated that the size categories behaves similarly only with respect to two of the most prominent explanatory variables $(\mathrm{B} / \mathrm{M}$ and Momentum). With respect to the other explanatory variables many differences are observed, some of these similar to what is observed on the NYSE and some quite different. 
It is also noted that when using equally weighted returns, the combined results for all stocks are usually dominated by Micro stocks, whereas Big stocks tend to dominate when using value weighted returns. Care should therefore be taken by a practitioner regarding the selection of the most appropriate measure for portfolio returns within a specific set of circumstances.

In conclusion is can be stated that our results are generally in line with previous results published on the behaviour of JSE listed shares as far as the size effect, the value stock effect and persistence of returns in the short run are concerned. It is found that stocks are weakly penalized for issuing more shares and that firm profitability is rewarded but only weakly so. Regarding accruals and asset growth different behaviour is observed in different size categories: larger stocks are rewarded but smaller stocks tend to be penalized for building assets.

While not exactly identical to, it can be stated that our results are in general consistent with the results obtained by Fama and French (2008) for stocks listed on the NYSE: the statistically more significant results confirm the findings of Fama and French, whereas differences are observed with respect to the less significant results.

In general this study provides further evidence against accepting the EMH in its strong or semi-strong form, as the information used is all publicly available. The fact that in several cases anomalous return performance is still present after compensating for risk provides proof that the explanatory variables that were investigated cannot all be viewed as proxies for some form of risk that would justify the observed stock return differentials. It is also demonstrated that the methodology as used in this work is of practical use both to verify the validity of the $\mathrm{EMH}$ within specific markets, as well as in the evaluation of the predictive value of specific fundamental indicators that can assist in the compilation of stock portfolios that can outperform the market on a risk-adjusted basis.

\section{ACKNOWLEDGEMENTS}

The author would like to acknowledge the assistance of the School of Business Mathematics and Informatics, including Thys Cronjé, at Northwest University for providing the stock data that was used for this work.

\section{REFERENCES}

Acharya VV and Pederson LH. 2005. Asset pricing with liquidity and risk. Journal of Financial Economics, 77(2): $375-410$.

Alcock J and Gray P. June 2005. Forecasting stock returns using model-selection criteria. The Economic Record, 81(253).
Auret C J and Sinclaire R A. 2006. Book-to-market ratio and returns on the JSE. Investment Analysts Journal, 63:31-38.

Altay E and Satman M K. 2005. Stock market forecasting: artificial neural network and linear regression comparison in an emerging market. Journal of Financial Management and Analysis, 18(2): 18 - 33.

Banz R W. 1981. The relationship between return and market value for common stocks. Journal of Financial Economics, 9:3-18.

Basiewicz PG and Auret CJ. 2009. Another look at the cross-section of average returns on the JSE. Investment Analysts Journal, 69:23 - 38.

Basiewicz PG and Auret CJ. 2010. Feasibility of the Fama and French three factor model in explaining returns on the JSE. Investment Analysts Journal, $71: 13-25$.

Bekiros S D. 2007. A neurofuzzy model for stock market trading. Applied Economics Letters, 14:53 - 57.

Bhana N. 2007. The market reaction to open market share repurchases announcements: the South African experience. Investment Analysts Journal, 65: 25 - 36.

Bhana N. 2008. The market reaction to capital expenditure announcements. Investment Analysts Journal, 68: $53-64$.

Blasco N, Del Rio C and Santamaria R. June 1997. The random walk hypothesis in the Spanish stock market: 1980-1992. Journal of Business Finance and Accounting, 24(5): 667 - 683.

Chan L, Hamao Y and Lakonishok J. 1991. Fundamentals and stock returns in Japan. Journal of Finance, 46:1739-1789.

Cubbin E, Eidne M, Firer C and Gilbert E. 2006. Mean reversion on the JSE. Investment Analysts Journal, 63: $39-48$.

Fama E F. 1970. Efficient capital markets: a review of theory and empirical work. Journal of Finance, 25:383417.

Fama E F and French K. 1992. The cross-section of expected stock returns. Journal of Finance, 47:427465.

Fama E F and French K R. 2004. The Capital Asset Pricing Model: Theory and Evidence. Journal of Economic Perspectives, 18(3): 25 - 46.

Fama E F and French K. 1993. Common risk factors in the returns of bonds and stocks. Journal of Financial Economics, 33: $3-56$. 
Fama E F and French K R. 2008. Dissecting Anomalies. The Journal of Finance, 63(4):1653 - 1678.

Fraser E and Page M. 2000. Value and momentum strategies: Evidence from the Johannesburg Stock Exchange. Investment Analysts Journal, 51: 25-35.

Graham M and Uliana E. 2001. Evidence of a valuegrowth phenomenon on the Johannesburg Stock Exchange. Investment Analysts Journal, 53: 7-18.

Huang W., Lai K K, Nakamori Y, Wang S and Yu L. 2007. Neural networks in finance and economic forecasting. International Journal of Information Technology and Decision Making, 6(1):113 - 140.

Jasic T and Wood D. 2004. The profitability of daily stock market indices trades based on neural network predictions. Applied Financial Economics, 14: 285 297.

Klerck W G and Maritz A C. 1997. A test of Graham's stock selection criteria on industrial shares traded on the JSE. Investment Analysts Journal, 45: 25-33.

Kluppelberg C., Maller R A, Van de Vyver M and Wee D. 2002. Testing for reduction to random walk in autoregressive conditional heteroskedasticity models. Econometrics Journal, 5: 387-416.

Lorek K S, Icerman J D and Abdulkader AA. 1983. Further descriptive and predictive evidence on alternative time-series models for quarterly earnings. Journal of Accounting Research, 21(1): 317 - 328.

Plaistowe T and Knight R F. 1986. Premium to book value may be a contrary indicator. Investment Analysts Journal, 28: 35-39.

Robins E M, Sandler M and Durand F. 1999. Interrelationships between the January effect market capitalisation and value investment strategies on the JSE. Investment Analysts Journal, 50: 53-64.

Sharpe W F. 1964. Capital asset prices: A theory of market equilibrium under conditions of risk. Journal of Finance, 19: 425-442.

Stoll HR and Whaley RE. 1983. Transaction costs and the small firm effect. Journal of Financial Economics, 12(1): $57-79$.

Van Rensburg P and Robertson M. 2003. Size, priceto-earnings and beta on the JSE Securities Exchange. Investment Analysts Journal, 58: 7-16. 